\title{
Signatures of the highly siderophile elements in the SNC meteorites and Mars: a review and petrologic synthesis
}

\author{
John H. Jones ${ }^{\mathrm{a}, *}$, Clive R. Neal ${ }^{\mathrm{b}}$, James C. Ely ${ }^{\mathrm{b}}$ \\ ${ }^{a}$ Mail Code: SR, NASA/JSC, Houston, TX 77058, USA \\ ${ }^{\mathrm{b}}$ Department of Civil Engineering and Geological Sciences, University of Notre Dame, Notre Dame, IN 46556, USA
}

Received 11 September 2002

\begin{abstract}
We have evaluated the highly siderophile element (HSE) signatures of the martian (SNC) meteorites using new and literature data. These Ir and Os concentrations correlate with the $\mathrm{Mg} \#[$ molar $\mathrm{Mg} /(\mathrm{Mg}+\mathrm{Fe})], \mathrm{Cr}$ and $\mathrm{Ni}$, suggesting that olivine or chromite acts as a host for compatible siderophiles. Our analysis agrees with others who have suggested that the martian mantle has chondritic relative abundances of siderophiles. We also agree that, unlike the $\mathrm{Sr}$ and $\mathrm{Nd}$ isotopic systems, there is no evidence from Os isotopes for crustal assimilation. Comparisons of the siderophile element ratios of ALH 84001 to younger SNCs give no indication of a change in the martian siderophile element pattern over time.
\end{abstract}

(C) 2002 Published by Elsevier Science B.V.

Keywords: SNC meteorites; Siderophile elements; Os isotopes; Core formation; Mars geochemistry

\section{Introduction}

The highly siderophile ("metal-seeking") elements $\mathrm{Ru}, \mathrm{Rh}, \mathrm{Pd}, \mathrm{Re}, \mathrm{Os}, \mathrm{Ir}, \mathrm{Pt}$ and $\mathrm{Au}$ are of interest to planetary scientists because they give insights into the early history of accretion and differentiation. By definition, these elements prefer to reside in the metal of planetary cores; and, therefore, highly siderophile elements (HSEs) residing in planetary mantles are considered to be overabundant relative to their known preferences for metal over silicate (Jones and Drake, 1986; Righter et al., 2000). Consequently, it has been inferred that processes other than equilibrium partitioning have been responsible for establishing the abundances of mantle siderophiles. A detailed under-

* Corresponding author. Tel.: +1-218-483-5319.

E-mail address: john.h.jones@jsc.nasa.gov (J.H. Jones). standing of the absolute concentrations and relative abundances of the highly siderophiles may therefore give important insights into the earliest history of a planet. Further, a subset of this group, Pt, Re and Os, contains the long-lived chronometers ${ }^{187} \mathrm{Re}-{ }^{187} \mathrm{Os}$ $\left(t_{1 / 2}=50\right.$ by $)$ and ${ }^{190} \mathrm{Pt}-{ }^{186} \mathrm{Os}\left(t_{1 / 2}=610\right.$ by $)$. Thus, the highly siderophile elements have assumed an importance much beyond their abundances, which are usually in the low to subparts per billion (ppb).

Terrestrially, observation has suggested that the HSEs were most likely added to the Earth late in its accretion, after core formation had ceased (Wänke, 1981; Chou et al., 1983). Consequently, it is believed that the Earth's primitive mantle contained these elements in nearly chondritic relative abundances (Chou et al., 1983; Morgan, 1986). During basalt petrogenesis Os and Ir behave highly compatibly and are retained in the source, whereas $\mathrm{Au}$ and $\mathrm{Re}$ 
act moderately to highly incompatibly and are concentrated in the liquid. Consequently, the continental crust has a high $\mathrm{Re} / \mathrm{Os}$ ratio and a highly radiogenic Os isotopic signature (e.g., Shirey and Walker, 1998). The behavior of the other four highly siderophiles are known with much less certainty. However, based on limited data from basalts, it appears that $\mathrm{Ru}, \mathrm{Rh}, \mathrm{Pd}$ and $\mathrm{Pt}$ have compatibilities that are intermediate to those of Ir and Au.

A more detailed account of the HSEs is not possible at this time. Even for the Earth, we do not know which phases accept Os and Ir, although the highest concentrations of these elements are found in ultramafic or chromite-rich assemblages. Therefore, there is a strong suspicion that olivine and/or chromite may play a role in producing the chondrite- or primitive mantle-normalized HSE patterns. Jones and Drake (1986) argued that sulfide is likely to not be a major host for Ir during basalt petrogenesis because it is likely then that $\mathrm{Au}$ would also be compatible. In summary, various studies have yielded very different inferences for Os and $\mathrm{Ir}$ compatibilities and large uncertainties remain (e.g., Brügmann et al., 1987; Shirey and Walker, 1998; Burton et al., 2002; Righter et al., 2000).

In this paper, we summarize what is known about the highly siderophile elements in the SNC meteorites. To anticipate our results, it appears that there are at least two distinct siderophile element signatures. Some $\mathrm{Re}-\mathrm{Os}$ isotope data are reinterpreted in light of this result. There is no evidence for temporal changes in these signatures with time. As others have argued, the abundances of the highly siderophile elements in the martian mantle may have been established by a late veneer, as is inferred for the Earth (e.g., Righter et al., 2000). But regardless of the how martian mantle HSE abundances were established, martian HSEs do approach chondritic ratios. HSE signatures show little correlation with other isotopic systems such as $\mathrm{Sr}$ and $\mathrm{Nd}$. In other words, HSE signatures are highly independent of lithologic type and petrologic history.

In the discussions below, we will use three different approaches in our evaluation of data: (i) agreement between analyses of different aliquots of a meteorite by a single analytical group; (ii) agreement between different analytical groups using different analytical techniques; and (iii) correlations between HSE and elements that are easier to analyze, because of their greater abundances. We will utilize both new data from Notre Dame, as well as literature data. The Notre Dame analytical techniques are documented in Ely et al. (1999) and Ely and Neal (2002). In addition, Table A2 compares Notre Dame analyses of PGE standard rock WITS-1.

\section{2. "Primitive" lithologies and the martian mantle}

Many of the parent magmas of the SNC meteorites, especially the shergottites, appear to have experienced various degrees of crustal interaction (e.g., Jones, 1989; Longhi, 1991). Other SNC meteorites are cumulates with variable amounts of cumulus minerals. Therefore, in order to avoid unnecessary confusion, some petrologic definition is necessary. Four samples that seem to have characteristics attributable to the martian mantle are: Chassigny, Dar al Gani 476, Dhofar 019 and QUE 94201 (Table 1). Chassigny is the type locality for martian mantle $\mathrm{Xe}$, which is very different from martian atmospheric Xe (Ott, 1988; Jakosky and Jones, 1997) and has a low initial ${ }^{87} \mathrm{Sr} /{ }^{86} \mathrm{Sr}$ (Nakamura et al., 1982). Dar al Gani 476 (hereafter DaG476), Dhofar 019 and QUE 94201 have highly radiogenic ${ }^{143} \mathrm{Nd} /{ }^{144} \mathrm{Nd}$ and low ${ }^{87} \mathrm{Sr} /{ }^{86} \mathrm{Sr}$, indicative of long-term residence in a reservoir depleted in incompatible elements (Borg et al., 1997, 2000, 2001; Taylor et al., 2000). Jones (1989) and Longhi (1991) have interpreted such $\mathrm{Sr}$ and $\mathrm{Nd}$ signatures to be those of the depleted martian mantle, and that interpretation will also be used here. Of course, there is no guarantee that past evaluations, based mainly on $\mathrm{Sr}$ and $\mathrm{Nd}$, will pertain to the HSEs. Processes that are not likely to affect $\mathrm{Sr}$ or $\mathrm{Nd}$ may severely disrupt the highly siderophiles, e.g. sulfide immiscibility or hydrothermal alteration. Nevertheless, we will endeavor to proceed, initially guided by lithophile indicators of crustal interactions.

We will temporarily postpone discussion of QUE94201, because it has experienced large degrees of crystal fractionation (e.g., McSween et al., 1996) and this process, too, can affect the HSEs (e.g., Puchtel and Humayun, 2001). Similarly, we postpone discussion of Dhofar 019 because its petrogenesis is still uncertain (e.g., Taylor et al., 2000). Thus, we will initially concentrate on Chassigny and DaG476, recognizing that even though we label these samples as 
Table 1

Summary of SNC meteorite lithologies

\begin{tabular}{lccll}
\hline Meteorite & Age $(\mathrm{my})^{\mathrm{a}}$ & Initial $\varepsilon\left({ }^{143} \mathrm{Nd}\right)^{\mathrm{b}}$ & ${\text { Initial } \gamma\left({ }^{187} \mathrm{Os}\right)^{\mathrm{c}}}^{\mathrm{c}}$ & Petrologic type \\
\hline Chassigny & 1340 & - & $\sim+6^{\mathrm{d}}$ & dunite (olivine cumulate) \\
EET 79001A & 173 & +16.6 & -0.9 & basalt with ultramafic xenoliths \\
ALH 77005 & 179 & +11.1 & +4.4 & olivine cumulate classified as a lherzolite \\
Nakhla & 1270 & +16 & -5.5 & augite cumulate \\
Shergotty & 165 & -7.3 & - & basalt with some cumulus pyroxene \\
Zagami & 177 & -4.7 & +3.3 & basalt with some cumulus pyroxene \\
Dar al Gani 476 & 474 & +36.6 & $-+10^{\mathrm{d}}$ & basalt with some cumulus(?) olivine \\
ALH 84001 & 4510 & -0 & -0.7 & orthopyroxenite \\
EET 79001B & 173 & +16.4 & - & basalt \\
QUE 94201 & 327 & +48 & +4.3 & basalt \\
LEW88516 & 178 & -8.2 & +3.0 & olivine cumulate classified as a lherzolite \\
Y793605 & - & - & - & olivine cumulate classified as a lherzolite \\
Dhofar 019 & 575 & +35 & - & basalt with some xenocrystic(?) olivine \\
Sayh al Uhaymir 005 & - & - & basalt with some cumulus(?) olivine \\
\hline
\end{tabular}

${ }^{a}$ Summarized by Nyquist et al. (2001).

${ }^{b}$ Borg et al. (2002), Borg et al. (2000), and Borg et al. (1997).

${ }^{\mathrm{c}}$ Brandon et al. (2000) and Walker et al. (2002).

${ }^{\mathrm{d}}$ This work.

'primitive,' they too are probably fractionated from their mantle sources.

Fig. 1 shows that, with two major exceptions (marked with arrows), the similarity between the

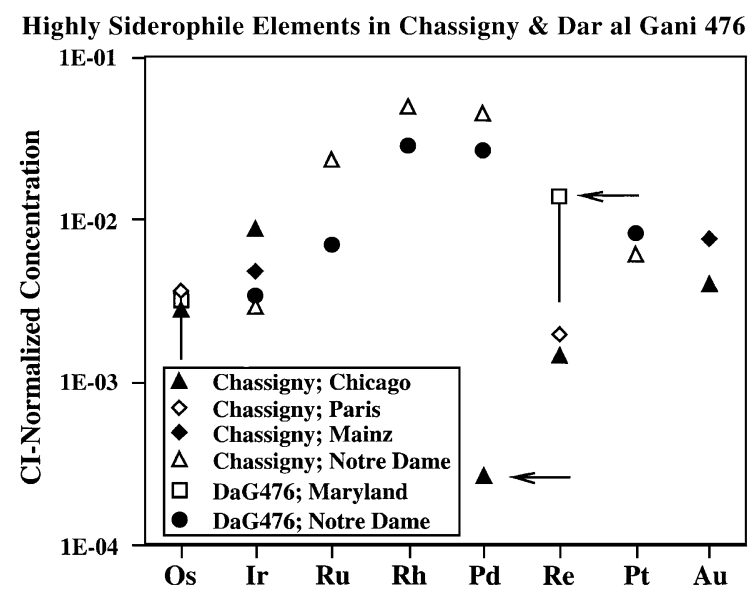

Fig. 1. CI-normalized concentrations of siderophiles in Chassigny and Dar al Gani 476. The agreement between these two meteorites for most elements is good. Two outliers (marked by arrows) are the Chicago Pd analysis of Chassigny and the Maryland Re analysis of $\mathrm{DaG}$ (see text). Ranges of Re and Os analyses of Chassigny by the Maryland group are shown as vertical lines. References for data: Chicago (Treiman et al., 1986); Paris (Birck and Allègre, 1994); Mainz (Burghele et al., 1983); Notre Dame (Ely and Neal, 2003); Maryland (Brandon et al., 2000). Chondrite normalizations in this paper were taken from Newsom (1995). two meteorites is striking. The exceptions are the low Pd analyzed by the Chicago group for Chassigny and the high Re analyzed in DaG476 by the University of Maryland group. We have no ready explanation for the Chicago Pd analysis of Chassigny, although this is conceivably a sampling problem. However, the similarity in the Notre Dame Pd analyses between Chassigny and DaG476 and the lack of strong fractionations between Rh and Pd lead us to prefer the Notre Dame Pd analysis of Chassigny. Similarities in other elemental analyses are also seen: Re (Chicago and Paris), Os (Chicago, Maryland, and Paris), Ir (Notre Dame, Chicago, Mainz) and Au (Chicago and Mainz), reinforcing the observation that these two meteorites have very similar siderophile element signatures.

The smaller discrepancy, the higher Re in DaG476, reported by the Maryland group $(0.5 \mathrm{ppb})$, deserves some discussion because this result affects the interpretation of the Os isotopic system. We strongly suspect that this Re enrichment is due to terrestrial contamination. DaG476 is a find from the North African desert. It contains terrestrial caliche and no leaching step was performed prior to Re analysis (A. Brandon, personal communication). Alternatively, this Re enrichment could have occurred on Mars (e.g., by crustal assimilation). However, those meteorites that we feel are most representative of the martian crust (e.g., Shergotty, Zagami; see below) do not have Re 
concentrations nearly as high as those reported by Brandon et al. (2000) for DaG476. Shergotty and Zagami have high $\mathrm{Re} / \mathrm{Os}$ ratios but relatively low $\operatorname{Re}(0.05-0.075 \mathrm{ppb})$.

On the other hand, the Brandon et al. (2000) Re analyses of DaG476 are reproducible (one Re analysis by ICPMS from U. of Chicago; Brandon et al., 2000). And the Re concentrations are high enough that contamination may be difficult. In light of these conflicting observations, it is difficult to uniquely interpret the Os isotopic data. Consequently, we offer two limiting calculations: (i) The $\mathrm{Re} / \mathrm{Os}$ ratio of DaG476 is correct as measured and the difference in Re between DaG476 and Chassigny reflects both the cumulate nature of Chassigny and the incompatibility of Re. In this scenario, the initial $\gamma$ Os for DaG476 is calculated from its age (474 my; Borg et al., 2000) to be $+0.8 \pm 0.2$ (Brandon et al., 2000). (ii) All the Re in $\mathrm{DaG} 476$ was added recently, possibly after arrival on Earth. In this case the measured Os isotopic composition is also the initial and would correspond to $\gamma \mathrm{Os}$ of +10.8 at $474 \mathrm{my}$. Both limiting calculations imply a martian mantle with a slightly superchondritic $\mathrm{Re} / \mathrm{Os}$ ratio and a $\gamma \mathrm{Os}$ of approximately +1 to +11 at 180 my. For reasons given below, we prefer the second of these calculations, implying a modern martian mantle with a $\gamma$ Os of about +11 .

How consistent is this range with the Os isotopic analyses of Chassigny? Two studies have investigated the Os isotopic composition of Chassigny: a single analysis by Birck and Allègre (1994) and five analyses by Brandon et al. (2000). Fig. 2 summarizes these data and illustrates an odd dichotomy. The Maryland group analyses (open symbols) are all subchondritic in terms of ${ }^{187} \mathrm{Os} /{ }^{188} \mathrm{Os}$ and the single Paris group analysis (solid symbol) is superchondritic. The data do not define an isochron; and the spread in $\mathrm{Re} / \mathrm{Os}$ was interpreted by the Maryland group to be due to recent Re contamination. (Fig. 1 indicates that the range of $\mathrm{Re} / \mathrm{Os}$ measured by the Maryland group is

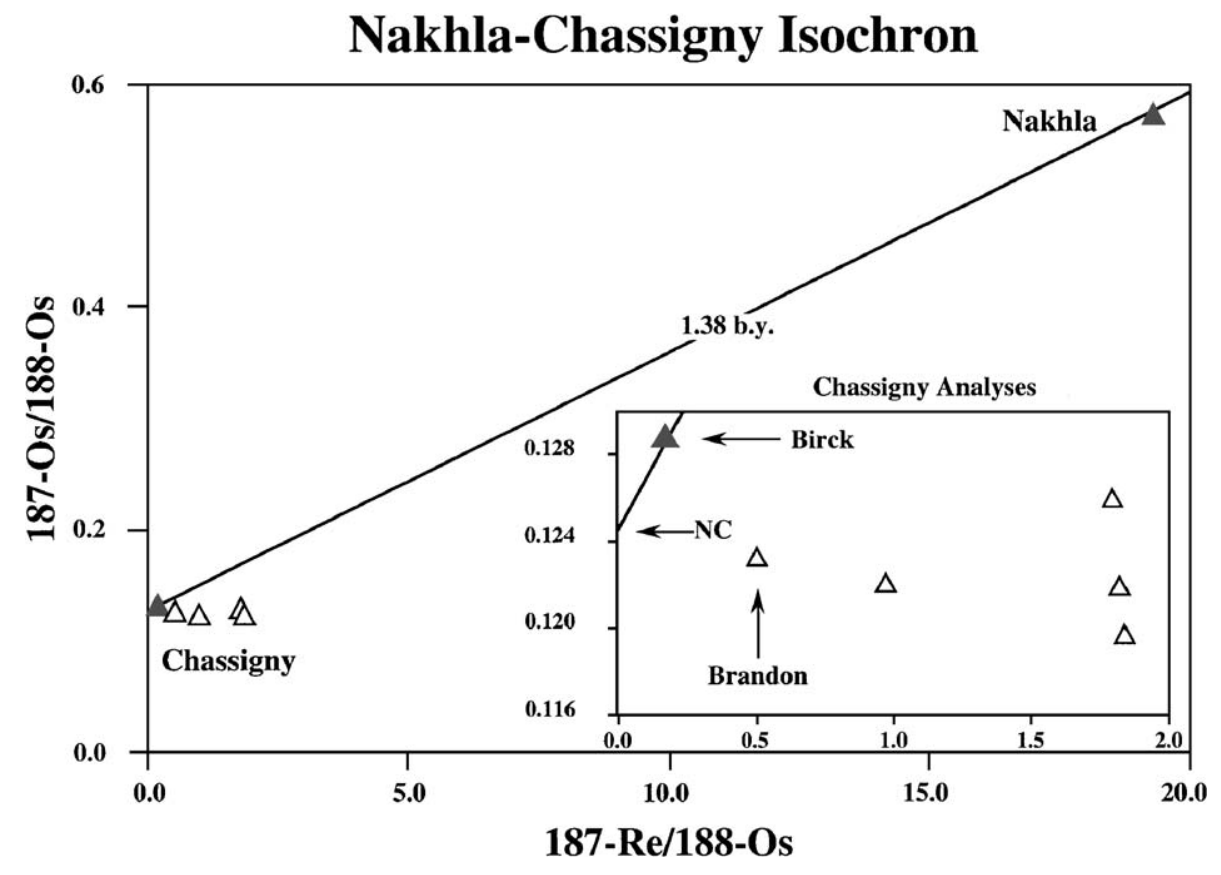

Fig. 2. Re-Os isochron diagram for Nakhla and Chassigny. Maryland data are from Brandon et al. (2000) and Paris data are from Birck and Allègre (1994). A whole-rock isochron drawn between the Maryland analysis of Nakhla and the Paris analysis of Chassigny (filled symbols) yields an age of 1.38 by, which is somewhat old compared to ages determined by other chronometers. If one of the Maryland group analyses of Chassigny were used instead (open symbols), the age would be older still. Inset is an enlargement of the low Re/Os and shows our preferred initial Os isotopic ratio for Chassigny and Nakhla $\left[\mathrm{NC}=+5.7 \gamma\left({ }^{187} \mathrm{Os}\right)\right]$. 
mainly due to variation in Re.) Therefore, there is no clear answer to the question of Chassigny's initial ${ }^{187} \mathrm{Os} /{ }^{188}$ Os.

Once again, we may attempt to bracket Chassigny's initial $\gamma$ Os, following the method of Brandon et al. (2000). Previous studies have suggested that the nakhlites and Chassigny are isotopically very similar and may be co-magmatic (Jones, 1989; Jagoutz, 1996). We may draw two "isochrons": one between Nakhla (Brandon et al., 2000) and the Chassigny analysis with the highest ${ }^{187} \mathrm{Os} /{ }^{188} \mathrm{Os}$ (Birck and Allègre); and one between Nakhla and the Chassigny analysis with the lowest ${ }^{187} \mathrm{Os} /{ }^{188} \mathrm{Os}$ (Brandon et al.). Both "isochrons" give ages of about $1.4 \pm 0.1$ by and are broadly consistent with the internal isochrons determined using other chronometer systems $(\sim 1.3$ by; Shih et al., 1996, 1998). The first isochron yields an initial $\gamma \mathrm{Os}$ of +5.7 , and the second yields an initial $\gamma$ Os of -39 . This very low initial is not possible, being lower than the initial value of the solar system. The Re-Os datum preferred by Brandon et al. (2000) gives an initial of -5.5 by this method, and we will accept that as a plausible lower limit to the true initial $\gamma$ Os of Chassigny. In terms of a modern mantle at 180 my, these model source regions will have $\gamma \mathrm{Os}$ of +7.3 and -6.8 , respectively. This range of $\gamma \mathrm{Os}$ broadly overlaps that of DaG476.

For internal consistency, we prefer the Chassigny Re analysis of the Paris group. We base this choice on four main factors: (i) If there has been recent $\mathrm{Re}$ addition (Brandon et al., 2000), the analysis of the Paris group has the lowest $\mathrm{Re} / \mathrm{Os}$ ratio, making it the least contaminated. (ii) The Re and Os concentrations measured by the Paris group are very similar to the analyses by the Chicago group. Thus, the Paris group's elemental concentrations (and Re/Os ratio) for Chassigny have been reproduced by another laboratory. (iii) This choice minimizes the NakhlaChassigny whole rock isochron age, which is slightly older than ages derived by other chronometers. (iv) If DaG476 and Chassigny both come from isotopically similar source regions, then the Re/Os of that mantle must be greater than chondritic, since the limiting calculations for DaG476 both implied source regions that were superchondritic in Re/Os.

Based on these considerations, our best estimate of the modern Os isotopic composition of the martian mantle corresponds to a $\gamma \mathrm{Os}$ of +7 to +11 . This estimate is in agreement with the recent analysis of Os in a magnetic separate from DaG476 by Walker et al. (2002), which yielded a $\gamma$ Os of +7.2. However, as should be clear from the foregoing discussion, any choice involves considerable selection from among the available data. The implications of our choice are that both DaG476 and Chassigny have experienced recent Re contamination or mobilization and that Chassigny contains, or has been contaminated with, heterogeneously distributed material with low ${ }^{187} \mathrm{Os} /{ }^{188} \mathrm{Os}$.

\section{3. "Evolved" lithologies and the martian crust}

The meteorites with the lowest $\varepsilon(\mathrm{Nd})$ and highest ${ }^{87} \mathrm{Sr} /{ }^{86} \mathrm{Sr}$ are Shergotty, Zagami and Los Angeles (Shih et al., 1982; Nyquist et al., 2000) and appear to have assimilated enriched crustal materials (Jones, 1989; Longhi, 1991). Consequently, the siderophile element signatures of these meteorites may be influenced by martian crust. Fig. 3 shows the CI-normalized siderophile element patterns for Shergotty and Zagami (no siderophile data exist yet for Los

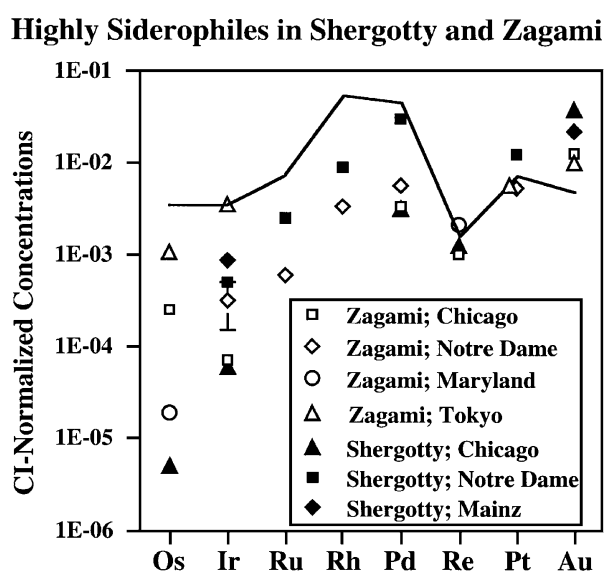

Fig. 3. CI-normalized concentrations of siderophiles in Shergotty and Zagami. Open symbols are for Zagami and solid symbols are for Shergotty. The line illustrates the Chassigny-DaG signature from Fig. 1. In general there is good agreement between analyses of Shergotty and Zagami. References for data: Chicago (Treiman et al., 1986); Mainz (Burghele et al., 1983); Notre Dame (Ely and Neal, 2003) Maryland (Brandon et al., 2000); Tokyo (Kong et al., 1999). Not plotted in the figure are INAA and RNAA Au analyses of Shergotty from the Mainz and Purdue groups, respectively. Averages of these unplotted Au analyses plot within the observed range (Laul et al., 1986). 
Angeles). Filled symbols are analyses of Shergotty; open symbols are analyses of Zagami.

The first feature of Fig. 3 that we would like to point out is the convergence of the data from the Chicago and Maryland groups for Re, which are also very similar to the Chicago and Paris data for $R e$ in Chassigny. To us this reinforces our conclusion from the preceding section that $\mathrm{DaG}$ has experienced terrestrial Re contamination. This interpretation implies that those samples of Chassigny that have high Re may also be contaminated.

As in the case of Fig. 1, there are quite significant variations between different analytical groups. Although the magnitudes of the discrepancies in Fig. 3 are not as large as in Fig. 1, they are more numerous. Palladium analyses vary by about an order of magnitude; Ir varies by about two orders of magnitude; and Os varies by nearly three orders of magnitude. For Os the Zagami analysis of Brandon et al. (2000) and the Shergotty analysis by the Chicago group are in reasonable agreement and are substantially lower than the Chicago and Tokyo analyses of Zagami. We prefer the lower Os values. We find it unreasonable that the Chicago Os/Ir ratio for Zagami is superchondritic. This is because Os and Ir appear to behave rather coherently during basaltic petrogenesis (Chou et al., 1983; our Fig. 1), although it is conceivable that Os is somewhat more compatible than Ir (e.g., Agiorgitis and Wolf, 1984; Puchtel and Humayun, 2001). (In fact, most of the Os/Ir ratios summarized in our paper are either chondritic or subchondritic.) And although the Tokyo Os/Ir ratio appears reasonable, the absolute concentrations are a factor of $\sim 100 \times$ higher than those of the Chicago group. Conceivably, this difference is due to sampling, but we do not believe this is the case. We will return to the issue of sampling heterogeneity below.

The variation in Ir analyses is large. The Tokyo Ir analysis of Zagami is much higher than the others and is similar to the Ir concentration of Chassigny (line in Fig. 3). The Notre Dame errors for Ir are fairly large, and the Zagami two-sigma error bar is shown in Fig. 3 (errors for other Notre Dame analyses are smaller than the symbols; errors for non-Notre Dame data are more difficult to estimate). Again, we prefer the Chicago Ir analyses because they agree better with the Os data.

The three analyses of $\mathrm{Pt}$ are all in reasonable agreement, and it is possible that the bulk partition coefficient for Pt is near unity. Three of the four Pd analyses from Notre Dame and Chicago agree, so we prefer these. A single Notre Dame Pd analysis of Shergotty is an outlier. Gold analyses of Zagami and Shergotty by the Mainz, Chicago and Tokyo groups are also in reasonable agreement.

Fig. 3 also compares the two basic elemental patterns that we have considered thus far, (i) Chassigny-DaG (line) and (ii) Shergotty-Zagami (data). The Shergotty-Zagami pattern is depleted in the more compatible HSEs, very similar in terms of Re and Pt, and slightly enriched in Au. Is the elemental pattern of the evolved suite that of the martian crust? Possibly, but we actually believe that the Zagami-Shergotty pattern does not represent crustal contamination but, rather, reflects an igneous fractionation event(s).

One reason for this conclusion is that the Nakhla siderophile pattern is very similar to that of Shergotty-Zagami. Fig. 4 compares the ShergottyZagami pattern (line inferred from Fig. 3) to that of Nakhla, a lithology thought to be closely related to Chassigny. Except for the Chicago Pd analysis and the Tokyo Os and Ir analyses, the Nakhla data match those of the Shergotty-Zagami pattern quite well. Nakhla and Chassigny both have initial $\varepsilon(\mathrm{Nd})$ of

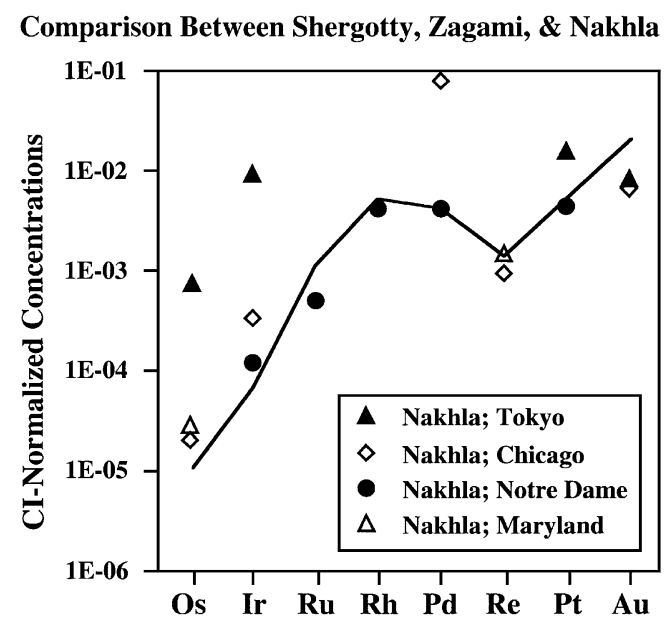

Fig. 4. CI-normalized concentrations of siderophiles in Nakhla. Line indicates the siderophile signature of Shergotty-Zagami from Fig. 3. The Nakhla signature is very similar to that of Shergotty and Zagami. Outliers are: the Tokyo analyses of Ir and Os and the Pd analysis from Chicago. References for data: Chicago (Treiman et al., 1986); Notre Dame (Ely and Neal, 2003); Maryland (Brandon et al., 2000); Tokyo (Kong et al., 1999). 
$\sim+15$ and ${ }^{87} \mathrm{Sr} /{ }^{86} \mathrm{Sr}$ of $\sim 0.7025$ (Shih et al., 1999) and therefore came from mantle source regions that had experienced long-term $\mathrm{Rb}$ and LREE depletion (e.g., Jones, 1989; Longhi, 1991). However, Nakhla itself is LREE-enriched. This suggests that the Nakhla parent magma was produced by very small degrees of partial melting ( $\leq \sim 1 \%$ ), such as has been proposed for lunar high-Ti basalts (e.g., Beard et al., 1998). Thus, it appears that both large degrees of fractional crystallization and small degrees of partial melting can produce similar siderophile element patterns. Unfortunately, at this juncture we cannot specify which phases are important in causing this fractionation.

A second reason for considering this pattern as "evolved" as opposed to "crustal" is that, based on the isotopic analyses of Brandon et al. (2000), there is not obviously any crustal Os in Zagami or Nakhla. We expect, based on terrestrial analogs, that the martian crust should be relatively enriched in Re and relatively depleted in Os, much like the Shergotty-ZagamiNakhla signature. But there is evidence from the $\mathrm{Rb}-$ $\mathrm{Sr}$ isotopic system that the martian crust formed at about 4.55 by (Jones, 1986; Shih et al., 1982; Harper et al., 1995). And a reservoir with a Re/Os ratio similar to that of Zagami ought to have a modern $\gamma \mathrm{Os}$ of about +2500 and such is not observed in any SNC. Fig. 5 shows that Zagami, ALH 77005 and
LEW 88516 form a Re-Os whole-rock "isochron" of 184 my (Brandon et al., 2000). This age is within error of those from other chronometer systems and implies an initial $\gamma \mathrm{Os}$ of +4.3 . This value is similar to, but slightly lower than, the mantle values determined from Chassigny and DaG476. Thus, there is no evidence that any of the Os in Zagami came from a reservoir having a long-term $\mathrm{Re} / \mathrm{Os}$ ratio similar to Zagami itself. We conclude, therefore, that the Shergotty-Zagami-Nakhla signature was formed by recent igneous fractionation, rather than crustal assimilation. This, in turn, implies that the $\mathrm{Re}-\mathrm{Os}$ and $\mathrm{Rb}-$ Sr systems are largely, if not completely, decoupled.

\section{Other SNC lithologies}

Thus far, we have characterized the highly siderophile element patterns of Chassigny, DaG476, Shergotty, Zagami, and Nakhla. By analogy, we predict that the other nakhlites, Lafayette and Governador Valadares, will have patterns similar to Nakhla and that the shergottite Los Angeles will be similar to Shergotty and Zagami. However, the lherzolitic shergottites, the A lithology of EET79001, and highly evolved basalts such as EET79001B, and QUE94201 are less easy to predict. In addition, new finds such as

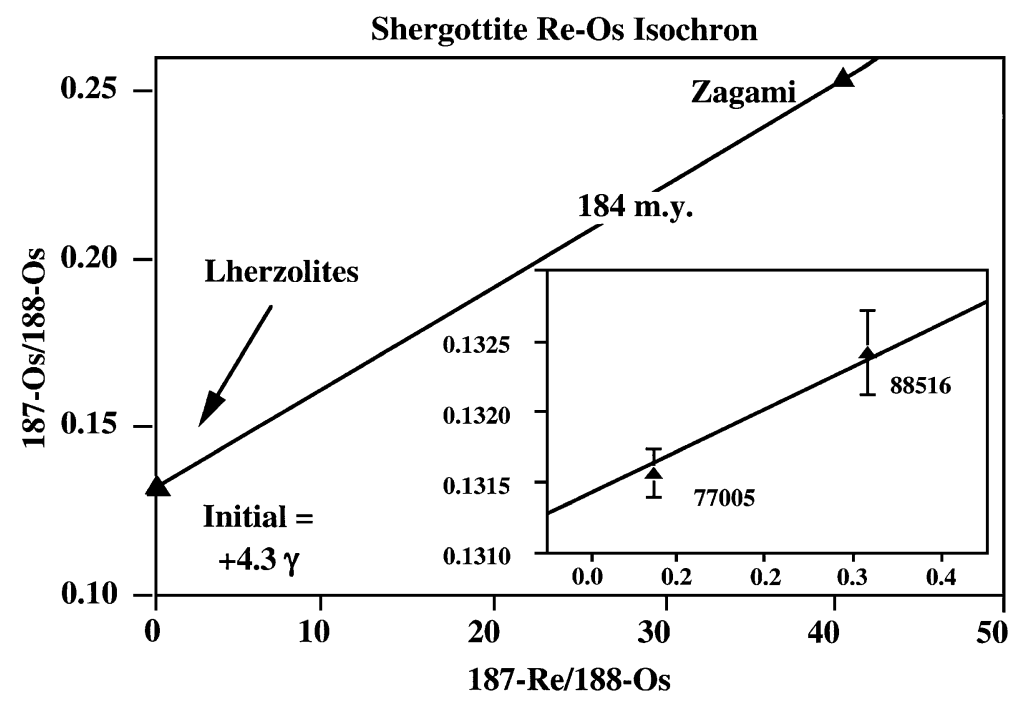

Fig. 5. Re-Os whole rock isochron diagram for Zagami, ALH 77005, and LEW 88516 (Brandon et al., 2000). The age of 184 my is in good agreement with other age determinations. The initial Os isotopic ratio is slightly super-chondritic. 
Dhofar 019 and Sayh al Uhaymir 005 (hereafter SaU 005) may not comfortably fit into the pre-existing SNC classification.

\subsection{Highly evolved lithologies: EET79001B and QUE94201}

Fig. 6 compares the highly siderophile element patterns of EET79001B and QUE94201 (hereafter QUE) to that of Shergotty-Zagami. Analyses of Ru, $\mathrm{Rh}, \mathrm{Pd}$ and Pt in Lithology B are very similar to those of Shergotty-Zagami, but no data are available for these elements in QUE. It is evident that Re and $\mathrm{Au}$ are generally lower in the highly evolved shergottites than in Shergotty-Zagami; and Ir and Os analyses show considerable scatter. Specifically, Ir varies by about a factor of $1000 \times$ in Lithology $\mathrm{B}$ alone, but overall the Lithology B pattern is reminiscent of that of Shergotty-Zagami. The QUE pattern, however, is seemingly flatter, with all four analyzed elements being $10^{-4}$ to $10^{-5} \mathrm{CI}$, but this may be due to the fact that only four HSE have been analyzed.

To us, there is some question as to what the real patterns for these samples should be. As we will show

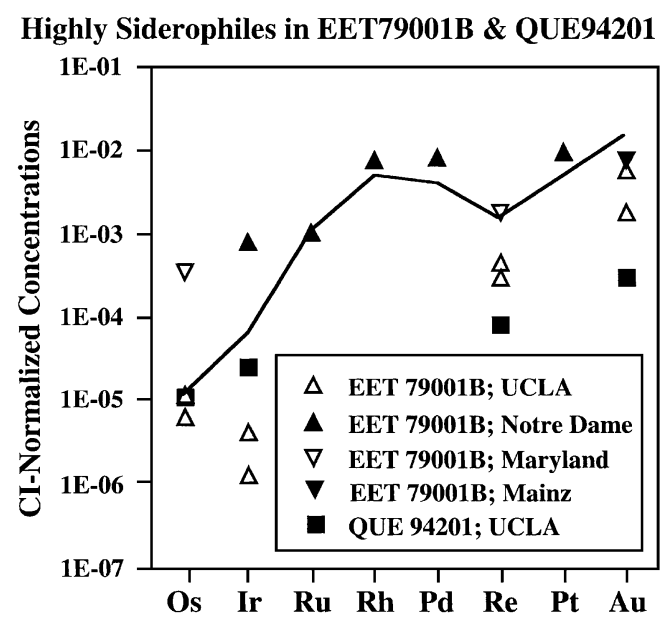

Fig. 6. CI-normalized concentrations of siderophiles in EET 79001B and QUE 94201. For QUE, the only analyses are from the UCLA group (solid squares). For Lithology B, solid triangles are from the Notre Dame group (Ely and Neal, 2003); and open triangles are from the UCLA (Warren et al., 1999) and Maryland (Brandon et al., 2000) groups. The line is the siderophile signature of Shergotty-Zagami from Fig. 3. No clear pattern for the evolved SNCs emerges. Part of the problem is due to sampling (see text).

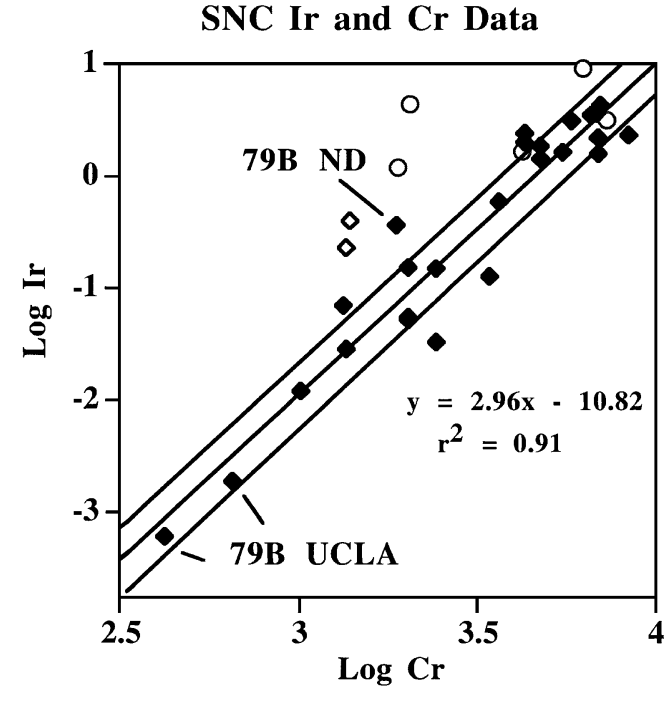

Fig. 7. $\log \mathrm{Ir}$ vs. $\log \mathrm{Cr}$ for the SNC suite. Filled symbols were used in the regression. Notre Dame $\mathrm{Cr}$ analyses have been combined with Chicago Ir analyses in order to plot the Chicago data (Chicago did not analyze for $\mathrm{Cr}$ ). Lines parallel to the regression line indicate a factor of $2 \mathrm{X}$ variation about the line. Open circles are from Tokyo and sometimes fall considerably above the regression line and were not included in the regression (see Figs. 4 , 6 and $8 \mathrm{a}$ ). In addition, the open diamonds are two analyses of Shergotty that appear nonrepresentative and were also not regressed (see text). In general, there is a good correlation between $\mathrm{Cr}$ and Ir. Differences in Ir between UCLA and Notre Dame analyses of EET 79001B are due to sampling, since both fall on or near the same trend as the other SNCs. Data from: Treiman et al. (1986), Ely and Neal (2003), Warren et al. (1999).

below, part of the confusion is due to sampling and the question of which sample, Lithology B or QUE, is more evolved. For example, the UCLA samples of Lithology $\mathrm{B}$ have lower $\mathrm{MgO}$ and higher $\mathrm{Al}_{2} \mathrm{O}_{3}$ than UCLA analyses of QUE (Warren et al., 1999), whereas analyses of these shergottites from other analytical groups can show just the opposite (e.g., Mittlefehldt and Lindstrom, 1996; Dreibus et al., 1996). Therefore, it is hard to judge which of these highly evolved compositions is most extreme.

For Lithology B, at least, it is clear that sampling errors are a major issue. Fig. 7 shows a correlation between Ir and $\mathrm{Cr}$ contents in SNC meteorites. Generally, the same sample that was analyzed for Ir was also analyzed for $\mathrm{Cr}$ (for exceptions see figure caption). In addition, the absolute abundance of $\mathrm{Cr}$ is about $10^{7}$ higher than for $\operatorname{Ir}$ (thousands of ppm versus sub-ppb), so Cr should be harder to contaminate and 
easier to analyze. Consequently, we believe that any correlation between a ppm-abundant siderophile and a ppt-abundant siderophile should be more robust than between two highly siderophiles that are subject to the inevitable problems of sampling, analysis, and contamination. A regression line has been drawn through the solid symbols and the parallel lines to either side represent a factor of $2 \times$ variation. Two open diamonds are analyses of Shergotty that appear less representative (one from Notre Dame and one from Mainz) and were not included in the regression. Open circles are data from the Tokyo lab that were also omitted (see figure caption).

Based on Fig. 7, Ir correlates well with $\mathrm{Cr}$ over a factor of $1000 \times$ range in Ir concentration. (A similar plot of Ir vs. Ni yields similar results, but in this case QUE plots off the trend. Either $\mathrm{Cr}$ is a better proxy for Ir than Ni or the UCLA Ni analysis for QUE is low.) However, both the Notre Dame and UCLA analyses of Lithology B fall on or near the trend, even though they differ in Ir contents by a factor of $\sim 100 \times$, and thus it is clear that sampling is an important issue for this lithology. Either the coarsegrained nature of Lithology $\mathrm{B}$ makes it difficult to sample or some samples of Lithology B have been taken too close to the indistinct $\mathrm{A}-\mathrm{B}$ contact. In terms of lithophile elements, the Lithology B sample analyzed by the Notre Dame group has basically the same La content as most other analyses of Lithology $\mathrm{B}$, whereas the UCLA samples have La concentrations that are $\sim 30 \%$ higher (see compilation in Meyer, 1998). Therefore, for reasons that are still unclear, the UCLA analyses of Lithology B have higher concentrations of incompatible elements and lower concentrations of compatible elements than other analyses. Despite this, the UCLA samples appear to fall on extensions of the general chemical trends seen in the SNC suite. Thus, the UCLA samples of Lithology B appear to be the most evolved SNC compositions yet analyzed. But the Lithology B samples analyzed by Notre Dame and UCLA are clearly of different materials.

We are suspicious of all analyses of Os from Lithology B and QUE. Traditionally, we have viewed Os as a good proxy for Ir and vice versa, although it could be, based on Fig. 4, that Os is slightly more compatible than Ir. Consequently, we view it as unlikely that the Os/Ir ratio of highly evolved lithol- ogies should be superchondritic, as the UCLA data imply.

The Os concentration of Lithology B from the Maryland group seems particularly high and we suspect that sampling errors of the type described above are again responsible. Compared to Maryland analyses of Lithology A, Lithology B does not seem particularly evolved. Using the UCLA analyses as a guide, $\mathrm{Ni}$ is $7-12 \times$ more depleted in Lithology $\mathrm{B}$ than in Lithology A. Similarly, Re in UCLA analyses appears to be $\sim 11 \times$ lower in Lithology B. By comparison, Os from the Maryland group is a factor of $3 \times$ lower in Lithology $\mathrm{B}$ and $\mathrm{Re}$ is only $1.5 \times$ lower. We suspect that the Maryland sample of Lithology B was contaminated with Lithology A material. The contact between Lithologies A and B is not sharp (McSween and Jarosewich, 1983) and shock melts of $\mathrm{A}$ and $\mathrm{B}$ have crossed the $\mathrm{A}-\mathrm{B}$ contact while preserving much of the chemical characteristics of the unshocked lithologies (Jones, 1986). Regardless, we believe that this is the scenario that best fits the data. Therefore, for the purposes of $\mathrm{Re}-\mathrm{Os}$ chronometry, it may be that an "isochron" drawn through analyses of Lithologies A and B is best thought of as a mixing line between two lithologies of similar age. This does not, however, invalidate the use of this line to infer an initial $\gamma$ Os.

An attempt to evaluate this hypothesis, using the JSC Curatorial sampling documentation, was not successful because of the lack of detailed information, such as the proximity of the Maryland sample of Lithology B, 416 to the A-B contact. However, a second sample of lithology B, selected by D. Mittlefehldt and analyzed by the Maryland group gave very different results: Re was 192 ppt, a factor of three higher than Brandon et al. (2000), and Os was below detection $(<10 \mathrm{ppt}$; Walker et al., 2002). This is in much better agreement with the UCLA Os analysis but in worse agreement with UCLA Re (see Table A1).

In summary, our interpretation of the highly evolved SNCs is that Os and Ir, which have deserved reputations for compatibility (in some phase), continue to become depleted as the magma fractionates. Gold and Re, which seemed incompatible when comparing the Chassigny-DaG and ShergottyZagami groups, seem to be acting compatibly in the QUE-Lithology B group. This is somewhat surprising but not out of the question, since lithophile trace 
elements become progressively more compatible as temperature decreases and silica activity of the liquid increases (e.g., Irving, 1978). The wide variation in Re, Os and Ir contents for samples that purport to all be aliquots of Lithology B is unsettling. More analy- ses are needed to better document the behaviors of extremely siderophile elements in these more highly evolved systems. However, correlations with elements such as $\mathrm{Ni}$ and $\mathrm{Cr}$ show promise for unraveling compatible HSE geochemistries.

\section{a Highly Siderophile Elements in Lherzolitic Shergottites}

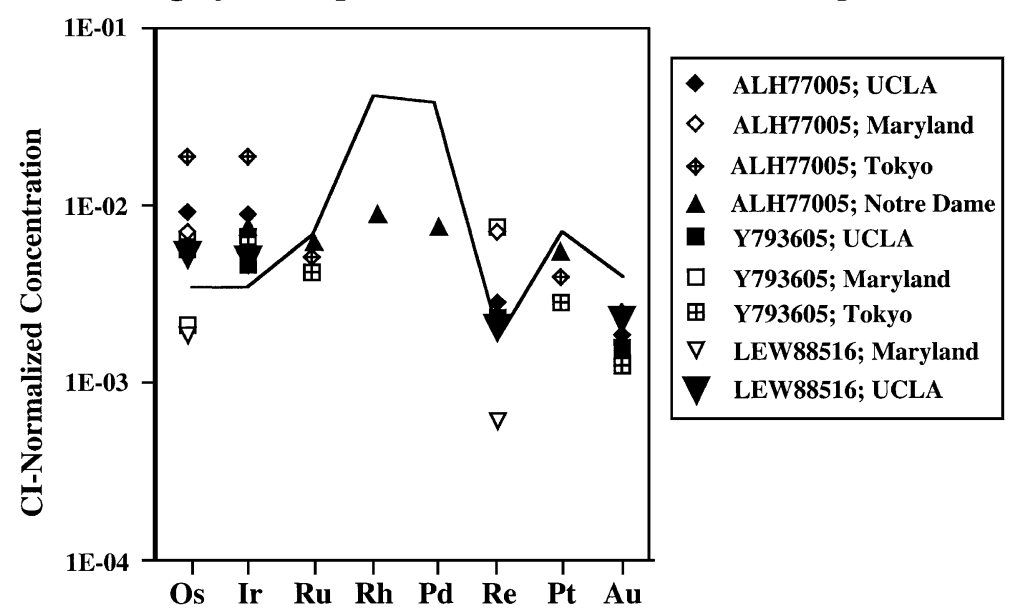

b Highly Siderophile Elements in EET79001A \& Dhofar 019

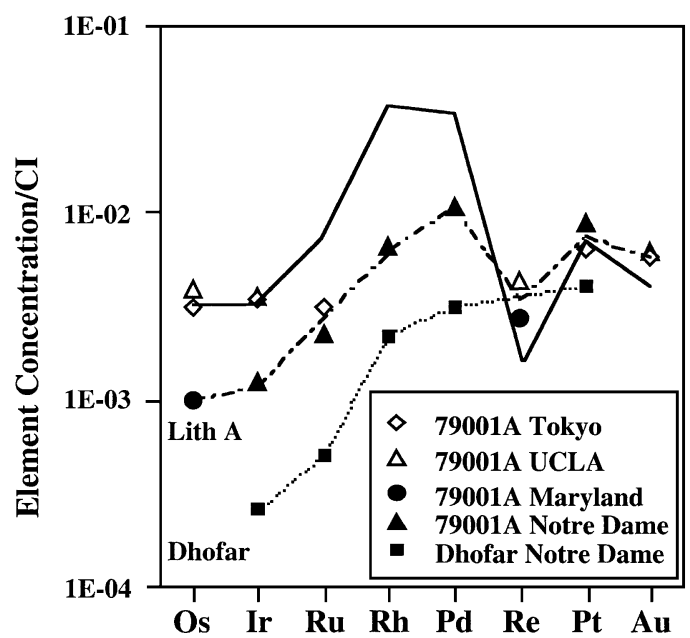

Fig. 8. (a) CI-normalized concentrations of siderophiles in lherzolitic shergottites. Line is the siderophile signature of Chassigny-DaG from Fig. 1. In general there is good agreement among siderophile analyses of different lherzolites. Although there are similarities between the lherzolites and Chassigny-DaG, there are also important differences. In particular, Rh and Pd are depleted in the lherzolites. Data are from UCLA (Warren and Kalleymeyn, 1996; Warren et al., 1999), Tokyo (Kong et al., 1999), Notre Dame (Ely and Neal, 2003), and Maryland (Brandon et al., 2000). (b) CI-normalized concentrations of siderophiles in EET 79001A and Dhofar 019. Solid line is the Chassigny-DaG signature; dashed line is for Lithology A; and the dotted line is for Dhofar. The siderophile signatures of Lithology A and Dhofar are unlike those of other SNCs. Data for Lithology A from Warren et al. (1999) and Kong et al. (1999); and data for Dhofar 019 from Neal et al. (2001) and Ely and Neal (2003). 
4.2. Other mafic lithologies: the lherzolites, EET79001A and Dhofar 019

\subsubsection{Lherzolites}

Fig. 8a shows that there is generally good agreement among the lherzolites (ALH77005; LEW88516; Y793605). Compared to Chassigny-DaG, Os and Ir are slightly elevated and $\mathrm{Pt}$ and $\mathrm{Au}$ are somewhat lower. Ruthenium and Re cluster near the Chassigny$\mathrm{DaG}$ line. However, $\mathrm{Rh}$ and $\mathrm{Pd}$ are significantly depleted relative to Chassigny-DaG. There is good agreement between analyses of: Os in ALH77005 (UCLA and Maryland), LEW88516 (UCLA), and Y796305 (UCLA and Tokyo); Ir analyses of ALH77005 (UCLA and Notre Dame), LEW88516 (UCLA), and Y793605 (UCLA and Tokyo); Ru analyses of ALH77005 (Tokyo and Notre Dame); Au analyses of all three lherzolites from UCLA and Tokyo; and Re from the several UCLA analyses of the lherzolites. Such agreements are to be expected because of the petrologic similarity of these three shergottites.

Outliers include: (i) low Re and Os for LEW88516 (Maryland); (ii) high Os and Ir for ALH77005 (Tokyo); and (iii) high Re for Y793605 and ALH77005 (Maryland). Some of these discrepancies are almost certainly due to sampling. For example, the Maryland Re and Os analyses of LEW88516 are much lower than those from the UCLA group (shown in Fig. 8a as a single average of three analyses). However, both groups report much the same Re/Os ratios for LEW88516. This is clearly an instance where some host phase(s) is being selectively sampled. However, some analytical problems may exist as well. We note again that the Tokyo Os and Ir analyses are often high compared to other labs, even though their Os/Ir ratio appears reasonable.

Broadly speaking, the total variation observed in the analyses of Fig. 8a is modest. Our preferred pattern for the lherzolites would be almost flat at $\sim 8 \times 10^{-3} \times \mathrm{CI}$ with negative anomalies for Re and $\mathrm{Au}$.

\subsubsection{EET79001A and Dhofar 019}

Fig. 8b summarizes data for EET79001A and Dhofar 019 (hereafter Lithology A and Dhofar). The $\mathrm{Re}, \mathrm{Pt}$ and Au analyses of Lithology A are similar to Chassigny and the overall patterns of Lithology A and
Dhofar are similar. The Os analysis of Lithology A from Maryland (Brandon et al., 2000) is about a factor of $3 \times$ lower than Os and Ir from UCLA and Tokyo, but is similar to the Ir analysis from Notre Dame. This is probably due to sampling since both UCLA analyses and the Notre Dame analysis of Lithology A fall on the Ir vs. Cr trend of Fig. 7. Lithology A contains xenocrystic material and is probably difficult to sample well. The $\mathrm{Ru}$ analysis from Tokyo agrees with that from Notre Dame; and the Re analyses from Maryland and UCLA are slightly high compared to our preferred value for Chassigny.

\subsubsection{Summary}

Fig. 9 summarizes our view of the mafic SNCs with respect to the highly siderophile elements, using our preferred values from Table $2 \mathrm{MgO}$ contents of the four SNCs plotted are given on the far left next to their normalized Os and/or Ir abundances. When normalized to Chassigny, an interesting pattern emerges. Zagami, a relatively evolved composition, forms a smooth, fractionated pattern that is strongly depleted in Os and Ir, modestly depleted in $\mathrm{Ru}, \mathrm{Rh}$ and $\mathrm{Pd}$, and whose $\mathrm{Au}, \mathrm{Pt}$ and $\mathrm{Re}$ concentrations are largely unchanged from those of Chassigny. As the $\mathrm{MgO}$ content of the samples increases, $\mathrm{Re}, \mathrm{Pt}$ and $\mathrm{Au}$

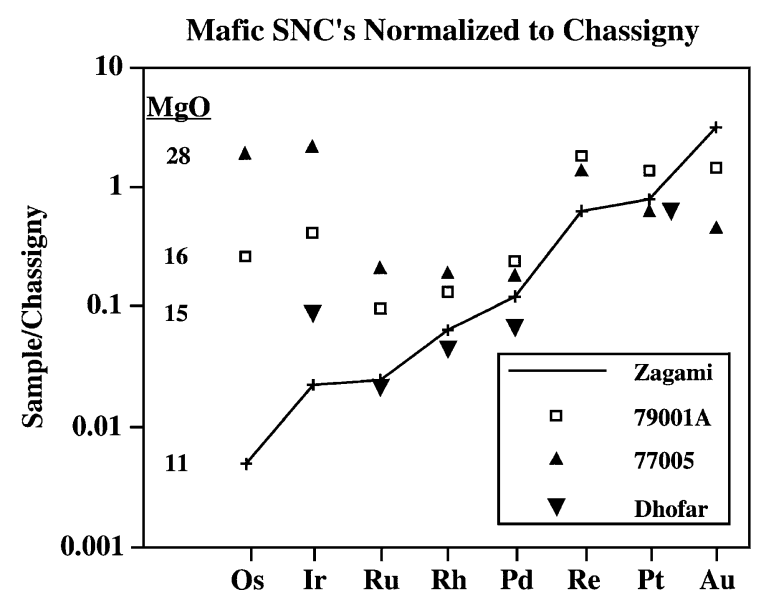

Fig. 9. Chassigny-normalized concentrations of siderophiles in mafic shergottites (Dhofar, Lithology A, and the lherzolites). For comparison a line connecting Zagami data is also shown. The Pt analysis of Dhofar is offset laterally for clarity. As $\mathrm{MgO}$ content increases, $\mathrm{Os}, \mathrm{Ir}, \mathrm{Ru}$, and $\mathrm{Rh}$ also increase; $\mathrm{Pd}, \mathrm{Re}$, and $\mathrm{Pt}$ remain largely unchanged; and Au appears to decrease. Data are from Table 2 , our preferred values. 
Table 2

Preferred values of highly siderophile elements in SNC meteorites (in ppb)

\begin{tabular}{|c|c|c|c|c|c|c|c|c|}
\hline Meteorite & $\mathrm{Ru}$ & $\mathrm{Rh}$ & $\mathrm{Pd}$ & $\mathrm{Re}$ & Os & $\mathrm{Ir}$ & $\mathrm{Pt}$ & $\mathrm{Au}$ \\
\hline Chassigny & 16.6 & 6.7 & 25.2 & 0.071 & 1.80 & 1.42 & 6.18 & 0.56 \\
\hline EET 79001A & 1.9 & 0.88 & 6.05 & 0.14 & 0.48 & 0.59 & 7.52 & 0.86 \\
\hline ALH 77005 & 4 & 1.3 & 4.67 & 0.10 & 4.4 & 4.3 & 4.62 & 0.26 \\
\hline Nakhla & 0.35 & 0.54 & 2.34 & 0.052 & 0.014 & 0.055 & 4.51 & 0.90 \\
\hline Shergotty & 1.8 & 1.16 & 1.7 & 0.044 & 0.0023 & 0.028 & 12 & 5 \\
\hline Zagami & 0.41 & 0.43 & 1.79 & 0.035 & 0.0091 & 0.033 & 5 & 1.57 \\
\hline $\mathrm{DaG}$ & 5.0 & 3.88 & 15.15 & 0.50 & 1.55 & 1.63 & 8.17 & 2.1 \\
\hline ALH 84001 & 0.26 & 0.16 & 1.14 & 0.0017 & 0.010 & 0.08 & 1.63 & 0.0094 \\
\hline EET 79001B & 0.74 & 1.03 & 4.46 & 0.014 & 0.0042 & 0.0012 & 9.26 & 0.52 \\
\hline QUE 94201 & - & - & - & 0.0028 & 0.0051 & 0.012 & - & 0.041 \\
\hline LEW88516 & - & - & - & 0.075 & 2.55 & 2.33 & - & 0.31 \\
\hline Y793605 & 3 & - & - & 0.084 & 2.7 & 2.2 & 2.79 & 0.22 \\
\hline Dhofar 019 & 0.35 & 0.30 & 1.7 & 0.370 & 0.031 & 0.13 & 4.0 & - \\
\hline $\mathrm{SaU} 005$ & - & - & - & $0.249^{\mathrm{a}}$ & 0.624 & - & - & - \\
\hline
\end{tabular}

${ }^{\mathrm{a}}$ Terrestrial contamination?

remain much the same. Ruthenium, $\mathrm{Rh}$ and $\mathrm{Pd}$ exhibit slight changes (especially $\mathrm{Ru}$ ) but the overall variation is not large. Conversely, Os and Ir change dramatically $(\sim 100 \mathrm{X})$ with ALH7705 having higher Os and Ir than Chassigny.

\section{Discussion}

\subsection{Interlaboratory comparisons for Re}

Our analysis indicates that the SNC suite can be accommodated, in a general way, in terms of three endmembers: primitive, evolved and highly evolved. Chassigny, DaG and the lherzolites seem most primitive, with Lithology A and Dhofar less so, and Shergotty and Zagami less still. These evolved compositions may then evolve further to Lithology B and QUE. Some of the observed variation among analyses of ostensibly the same materials can be explained by inadequate sampling, but some disagreements are probably analytical.

Using Re and Os data generated by various laboratories, we have plotted $\log (\mathrm{Re} / \mathrm{Os})$ vs. $\log (1 / \mathrm{Os})$ in Fig. 10. The two lines are regressions through the $\mathrm{Re}-$ Os data from the Maryland group (open diamonds) and through data from other laboratories (solid triangles). The datum labeled 84 is ALH84001, an orthopyroxenite cumulate, and the most serious outlier of either regression (see section on ALH84001 below). Also plotted are five analyses of Chassigny (open circles) from the Maryland group. These analyses are consistent with the regression of the other Maryland data but are not included in it because of possible terrestrial Re contamination.

Because Os is in the denominator of both axes, no information about Os is gained from diagrams such as Fig. 10. Fig. 10 is simply a convenient means of

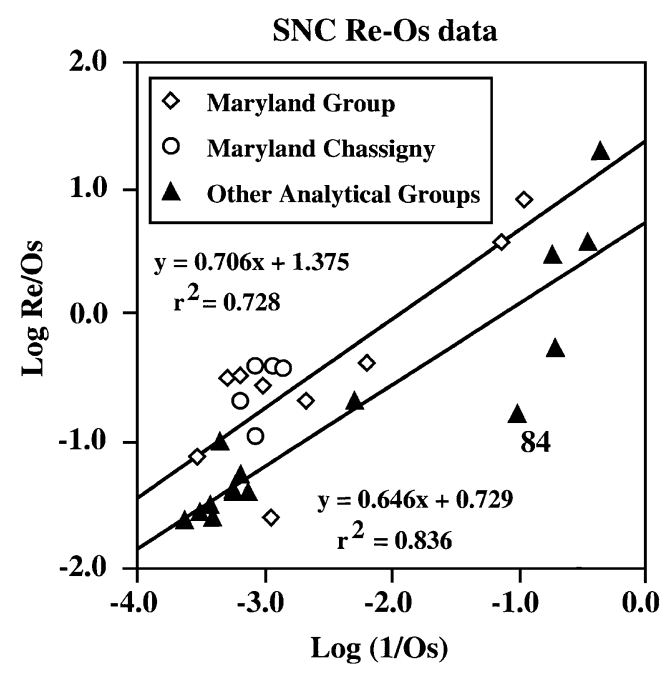

Fig. 10. Log Re/Os vs. log (1/Os). Open symbols are Maryland analyses; filled symbols are from UCLA, Chicago, and Paris, but are dominated by UCLA analyses. There appears to be a systematic $\sim 3 \times$ difference between the two sets of analyses. The reason for this difference is unknown. For detailed discussion, see text. 


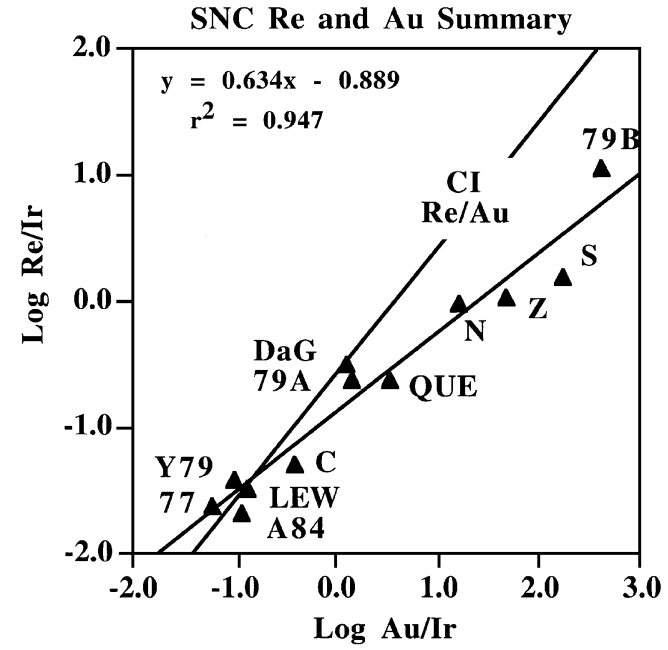

Fig. 11. Log Re/Ir vs. $\log \mathrm{Au} / \mathrm{Ir}$. Our preferred values of Re, Au, and Ir for the SNC suite (Table 2). Changes in location on this plot are mainly attributable to changes in Ir concentration. SNCs that are most primitive (in terms of mantle derivation) have nearly chondritic $\mathrm{Re} / \mathrm{Au}$ ratios. Evolved lithologies have lower $\mathrm{Re} / \mathrm{Au}$ ratios.

comparing Re data between different laboratories. As can be seen, the regressions are subparallel, but there is little overlap between the two regressed datasets. Taken at face value, Fig. 10 implies that there is a systematic difference between the Maryland group analyses and those of others. This difference is about a factor of $3 \times$ (difference of the two $y$-intercepts). Although there are a few analyses in Fig. 10 from the Chicago and Paris groups, the "non-Maryland" dataset is dominated by UCLA data.

Little insight is gained by using third-party labs as arbiters. For example, the Chicago Re/Os analysis of Shergotty is more consistent with the Maryland trend but the Paris analysis of Chassigny falls on the "others" trend. However, the disagreements between Re analyses of SNCs are qualitatively very similar to disagreements between Re analyses of terrestrial mantle xenoliths. Meisel et al. (2001) have shown that Re analyses of the Basaltic Volcanism Ultramafic Suite by the Maryland group are, on average, a factor of $3 \times$ higher than those of Morgan and co-workers who analyzed them by RNAA (Basaltic Volcanism Study Project, 1981).

In our view, it is difficult for the observed spread of data in Fig. 10 to be entirely attributed to sampling, given the relatively large number of analyses conducted. (Although, as we discussed above, the Maryland datum with the lowest Re concentration (LEW88516) has the same Re/Os ratio as the UCLA analyses. This difference and differences in the analyses of Lithology B probably $d o$ represent sampling.) It appears to us that in the case of Re there is some analytical problem. Even so, the situation is still murky. If, for example, there were a standardization problem such that all Maryland Re analyses were high by a factor of $3 \times$, then isochrons generated by that lab would be seriously in error. On the other hand, those samples with "high" Re tend to have low Re/Os ratios. Errors in the Re content of these samples can affect the inferred initial Os but might not greatly affect the isochron age. We offer no resolution to this issue except to note that more interlaboratory comparisons are desirable.

\subsection{Systematics between elements}

Figs. 11-15 give detailed relationships between various HSE pairs, using Ir as a normalization. In

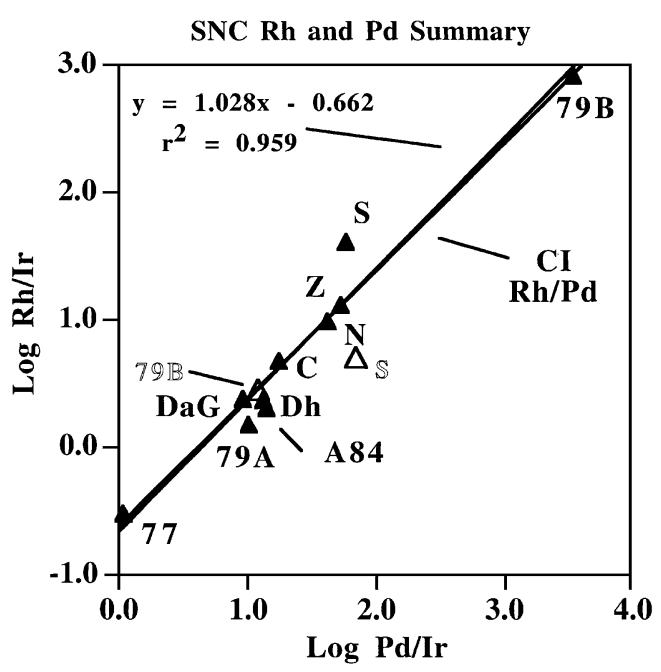

Fig. 12. $\log \mathrm{Rh} / \mathrm{Ir}$ vs. $\log \mathrm{Pd} / \mathrm{Ir}$. The $\mathrm{Rh} / \mathrm{Pd}$ ratio of the $\mathrm{SNC}$ suite is indistinguishable from chondritic. Two different analyses of Shergotty and EET 79001B are plotted, with our preferred values as solid symbols. In the case of EET 79001B, it is probable that the low Pd/Ir analysis was contaminated with material from Lithology A (see text). Variation in siderophiles between analyses of Shergotty probably also reflects sampling. 


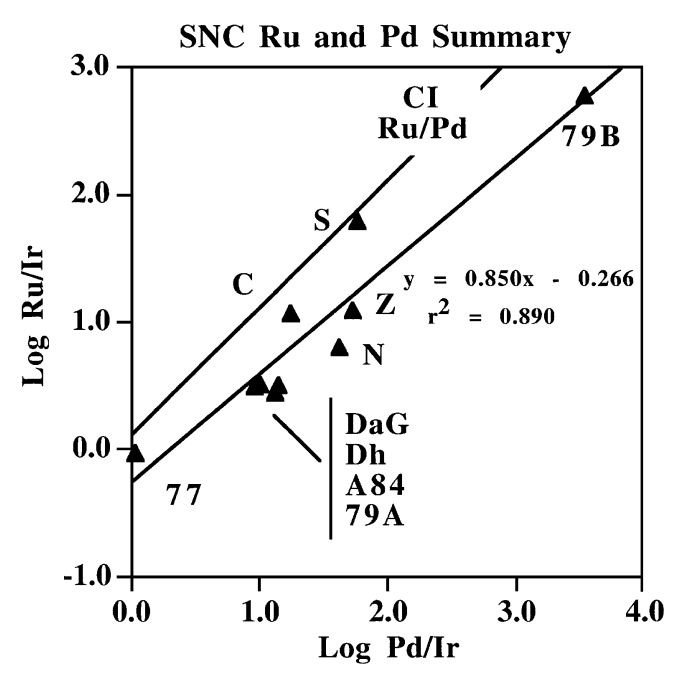

Fig. 13. $\log \mathrm{Ru} / \mathrm{Ir}$ vs. $\log \mathrm{Pd} / \mathrm{Ir}$. The $\mathrm{Ru} / \mathrm{Pd}$ ratio of most SNCs is subchondritic (Table 2). Some process has fractionated $\mathrm{Ru}$ from $\mathrm{Pd}$ and Rh, possibly spinel partitioning (Capobianco and Drake, 1990).

these figures, unless designated otherwise, we use our preferred values for these elements (Table 2). We have chosen to use ratio plots for two reasons: (i) Several of the SNCs are cumulates and are less amenable to plots that use absolute concentrations; and (ii) plots with Os or Ir in the denominator are useful for creating a

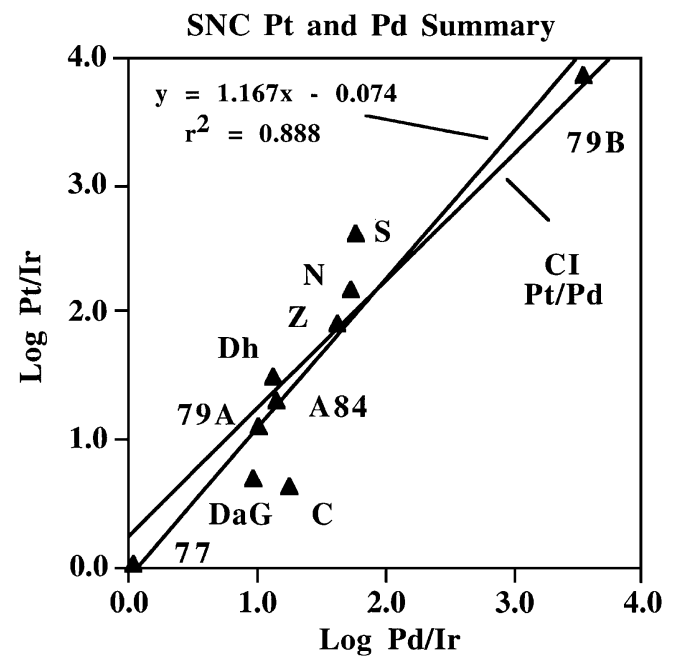

Fig. 14. Log Pt/Ir vs. log Pd/Ir. As in the case of Rh/Pd, Pt/Pd (Table 2) clusters about the chondritic value.

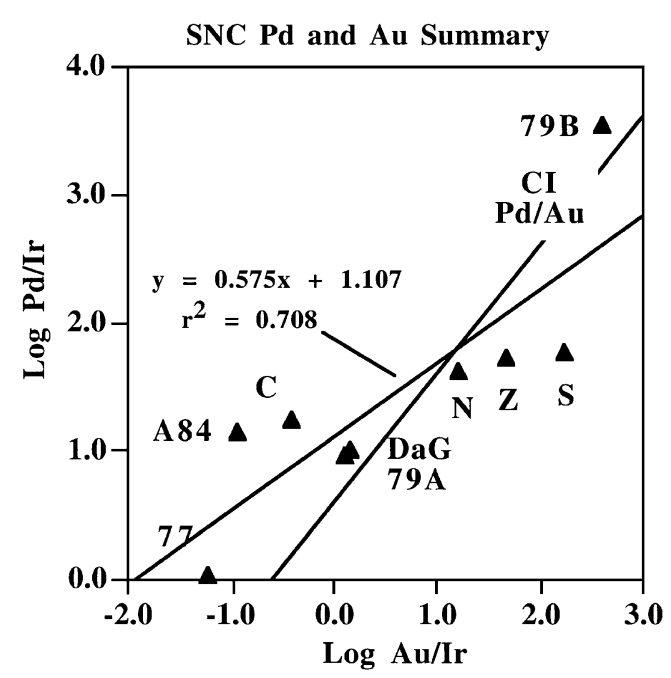

Fig. 15. Log Pd/Ir vs. $\log \mathrm{Au} / \mathrm{Ir}$. Most SNCs have Pd/Au ratios that are not far removed from chondritic (Table 2).

spread in the data. Most of the dynamic range in Fig. 11 is not due to variations in $\mathrm{Au}$ and $\mathrm{Re}$, but to variation in Ir (e.g., Fig. 9). As can be seen in Fig. 11, the $\mathrm{Re}-\mathrm{Au}$ data express a regularity with primitive SNCs having a nearly CI Re/Au ratio; evolved SNCs possessing a lower Re/Au ratio; and highly evolved SNCs such as QUE trending back toward the CI value. The regression trend is consistent with recent interpretations that the highly siderophile elements exist at or near chondritic relative abundances in the martian mantle (Warren et al., 1999; Righter et al., 2000). A possible problem with this view is that most SNCs come from depleted mantles (e.g., Jones, 1989). Consequently, it may be that the signature we have termed "primitive" is itself significantly fractionated from bulk silicate Mars.

This issue is not necessarily resolved by looking at $\mathrm{Ru}, \mathrm{Rh}, \mathrm{Pt}$ and $\mathrm{Pd}$. Fig. 12 shows that the $\mathrm{Rh} / \mathrm{Pd}$ ratio of SNCs is very close to that of CI chondrites. Absolute abundances of Rh and Pd vary by about an order of magnitude; and their relatively high concentrations in Chassigny make it appear that these elements act moderately compatibly. We noted above that the Notre Dame Pd analysis of Shergotty appeared high. Despite that, we have plotted that analysis on Fig. 12 (open symbol) because the Rh/ $\mathrm{Pd}$ ratio seems consistent with the other analyses. We conclude that the Shergotty analysis by the Notre 
Dame group is high because of sampling, and not because of contamination or analytical problems. We also note that the Notre Dame Pd/Ir ratio for Shergotty is similar to the Chicago analysis, even though Pd and Ir concentrations from these two labs differ by an order of magnitude. Possibly, Pd and Ir are sited similarly in Shergotty.

Fig. 13 shows $\log (\mathrm{Ru} / \mathrm{Ir})$ vs. $\log (\mathrm{Pd} / \mathrm{Ir})$. Pd data are as in Fig. 12 and the Ru data are from Notre Dame and Tokyo. Ruthenium, too, is concentrated in Chassigny. However, in Fig. 13 the data are most consistent with a fairly constant $\mathrm{Ru} / \mathrm{Pd}$ ratio that is about $2 \times$ below CI. This is puzzling. Apparently Ru and $\mathrm{Pd}$ do not readily fractionate during martian igneous processes, otherwise the $\mathrm{Ru} / \mathrm{Pd}$ ratio would not be so constant, even though in terrestrial systems they may fractionate (e.g., Capobianco and Drake, 1990, 1994; McCandless et al., 1999). For the $\mathrm{Ru} / \mathrm{Pd}$ ratio to be absolutely constant, the regression line of Fig. 13 should have a slope of 1.0 , and in fact the regression has a slope of 0.85 which may be indistinguishable from unity. If $\mathrm{Ru}$ and $\mathrm{Pd}$ do not readily fractionate, why are $\mathrm{SNC} \mathrm{Ru} / \mathrm{Pd}$ ratios less than $\mathrm{CI}$ ? Either some early(?) fractionation occurred that changed the $\mathrm{Ru} / \mathrm{Pd}$ ratio of the martian mantle, or the Notre Dame Ru analyses are systematically low by about a factor of $\sim 2 \times$. Neither of these alternatives seems attractive. Comparisons between the Notre Dame and Tokyo Ru analyses are generally good. Possibly, the Ru depletion of SNCs is attributable to the greater compatibility of $\mathrm{Ru}$ in spinel, relative to $\mathrm{Rh}$ and $\mathrm{Pd}$ (Capobianco and Drake, 1990). More partitioning data are needed to evaluate this suggestion. Fig. 14 shows $\log (\mathrm{Pt} / \mathrm{Ir})$ vs. $\log (\mathrm{Pd} / \mathrm{Ir})$. Platinum data are from Notre Dame and Tokyo. Pt/Pd ratios of SNCs are, like Rh/ $\mathrm{Pd}$, approximately chondritic.

Systematic deviation from CI ratios was seen in analyses of Re/Au (Fig. 11). Fig. 15 shows $\mathrm{Au}$ and Pd data from the UCLA, Chicago, Tokyo and Mainz groups, indicating that most $\mathrm{SNCs}$ have $\mathrm{Pd} / \mathrm{Au}$ ratios that scatter about the CI ratio and do not deviate greatly from it.

It is clear that fractionations between $\mathrm{Rh}, \mathrm{Pd}$ and $\mathrm{Pt}$ are not large. These observations strengthen the suggestion that the martian mantle has CI relative abundances of the highly siderophile elements. $\mathrm{Ru}$ and $\mathrm{Au}$ are more problematic. But in the case of $\mathrm{Re} / \mathrm{Au}$, the more primitive lithologies have nearly CI relative abundances for these elements, even if the evolved lithologies do not. Our study reinforces earlier suggestions that martian mantle may have chondritic relative abundances of HSE (e.g., Brandon et al., 2000).

\subsection{The ALH84001 source region}

One interpretation of the very low HSE abundances in ALH84001 is that there has been a change in the siderophile element content and redox state of the martian mantle over time (Warren and Kalleymeyn, 1996). The foregoing Figs. 11-15 include analyses of ALH84001, and these analyses are entirely consistent with the overall SNC trends. In our view, the very low siderophile element contents of ALH84001 are best explained either (i) by the cumulate nature of that lithology or (ii) by a process such as sulfide fractionation. We favor the latter process mainly because the cumulate model would not explain the very low Ni abundance of ALH84001. Ni should enter orthopyroxene compatibly, and the very low $\mathrm{Ni}$ content of ALH84001 pyroxenes requires another explanation, such as extensive olivine or sulfide removal.

Thus, we suggest that immiscible sulfide liquids formed during the crystallization of the ALH84001 parent liquid. These liquids are required to efficiently scavenge the HSE and Ni from the silicate liquid. The low abundance of these elements in ALH84001 further requires that these sulfides be efficiently excluded during the cumulate process. In this model, HSE ratios are preserved in ALH84001 by minor trapping of sulfide, whereas absolute abundances are greatly suppressed.

In addition, the systematics displayed in the foregoing figures, among meteorites whose ages vary from $\sim 180$ my to $\sim 4.5$ by, do not indicate that the source regions for these basalts have appreciably evolved over time with respect to the HSE. We see no evidence to invoke temporal evolution of the SNC source regions.

\subsection{Crust-mantle fractionation}

Our choices of siderophile element abundances for our various types of SNCs have been somewhat arbitrary in a few cases. We have attempted to 
evaluate our primitive and evolved siderophile signatures by looking at the general pattern of crustmantle fractionation. Fig. 16 shows one simple version of this attempt. Here we have taken "primitive" (Chassigny) and "crustal" (Shergotty/Zagami) patterns and ratioed them to each other (solid triangles) as apparent $D$ (crust/mantle). For comparison, we have taken estimates of the depleted terrestrial upper mantle and fresh MORB and ratioed them in the same way (open diamonds). In general, the agreement is good. The two clear exceptions are Ir and Re. The reasons for these discrepancies are very uncertain. Considering all the uncertainties and the difficulties associated with sampling and analysis, we should probably be pleased that our Earth-Mars comparison is as good as it is. We cannot rule out the possibility that there are mineralogical controls on Ir and Re partitioning that differ between Earth and Mars. In our view, it is more likely that there could be differences in redox conditions between Mars and the Earth (e.g., Wadhwa, 2001) that translate into different valence states for some elements.

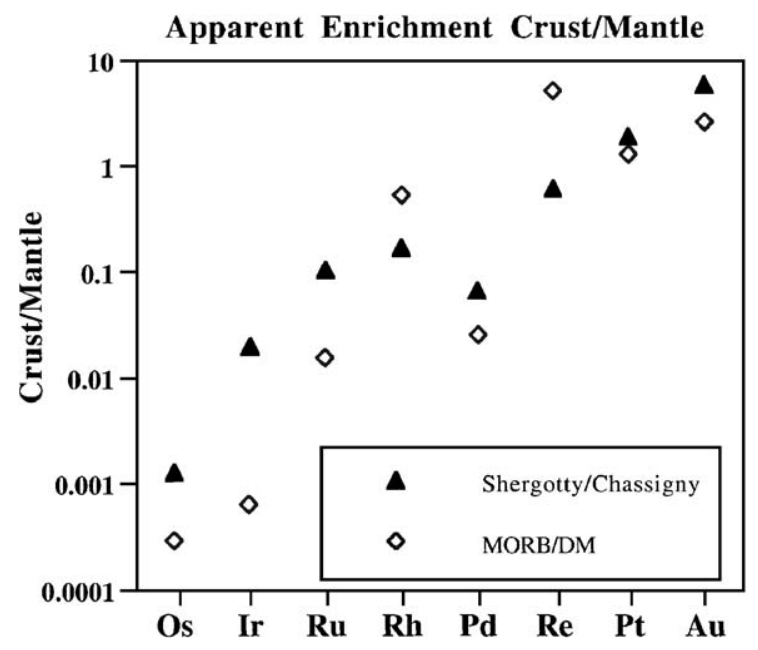

Fig. 16. Apparent partition coefficients D (basalt/mantle) for Mars and the Earth. Solid symbols are ratios of elemental concentrations for Shergotty/Chassigny (this work). Open symbols are MORB analyses normalized to estimates for siderophile element concentrations in the Earth's depleted upper mantle. Depleted upper mantle data from the GERM website. MORB analyses are from: OsSchiano et al. (1997); Ir, Ru, and Pd-Rehkämper et al. (1999); $\mathrm{Au}$-Chou et al. (1983); Re-Basaltic Volcanism Study Project (1981); Rh—GERM website; Pt—Rehkämper et al. (1999) and Puchtel and Humayun (2001).

\subsection{Isotopic considerations}

\subsubsection{Crustal interactions}

As Brandon et al. (2000) and this study have emphasized, the large range of $\mathrm{Nd}$ and $\mathrm{Sr}$ isotopic compositions observed in the SNC suite is not seen in the $\mathrm{Re}-\mathrm{Os}$ system. The total range of initial Os in the SNC suite is $\sim 10 \gamma$. This modest range in Os isotopic composition is surely not because of a lack of $\mathrm{Re}-\mathrm{Os}$ fractionation on Mars. Re/Os ratios of SNCs vary from 0.04 (Chassigny) to $\sim 20$ (Shergotty) - a range large enough to cause very large isotopic variations. However, if Shergotty or Zagami is viewed as being most similar to the martian crust, then the SNCs have experienced no measurable assimilation of crustal Os.

\subsubsection{Siderophile signatures of different mantle reservoirs}

Some of the isotopic variation among SNCs may not reflect crustal interaction, but may be due to either mantle heterogeneity or to sampling of different mantle reservoirs. Possible candidates for different $\mathrm{Sr}-\mathrm{Nd}$ reservoirs include: QUE94201 $\left(\varepsilon\left({ }^{143} \mathrm{Nd}\right) \sim+50\right.$ and $\left.{ }^{87} \mathrm{Sr} /{ }^{86} \mathrm{Sr} \sim 0.7013\right)$, NakhlaChassigny (nakhlites fall off the shergottite $\varepsilon\left({ }^{143} \mathrm{Nd}\right)-$ $\varepsilon\left({ }^{142} \mathrm{Nd}\right)$ isochron), and EET79001 (elevated ${ }^{206} \mathrm{P} /$ ${ }^{204} \mathrm{~Pb}$ relative to the other shergottites) (Borg et al., 2000; Borg et al., 2001; Jones, 1989). However, even for the Nakhla-Chassigny reservoir, the siderophile element signatures of Nakhla and Chassigny are nearly as different as it is possible to be. Conversely, Nakhla and Shergotty have very similar siderophile signatures but extremely different $\mathrm{Sr}$ and $\mathrm{Nd}$ isotopic characteristics. These observations suggest that the siderophile signatures of SNCs were acquired recently and are strongly decoupled from lithophile element fractionations.

\subsubsection{Correlations between $\mathrm{Pb}$ and $\mathrm{Os}$}

Brandon et al. (2000) found that there was no good correlation between $\mathrm{Os}$ and either $\mathrm{Nd}$ or $\mathrm{Sr}$ isotopes. However, it is possible, using our revisionist values for $\gamma \mathrm{Os}$ that there is a correlation between $\mathrm{Os}$ and $\mathrm{Pb}$. Fig. 17 shows data from those SNCs that have been analyzed for both $\mathrm{Pb}$ and Os. We predict, based on Fig. 17, that DaG 


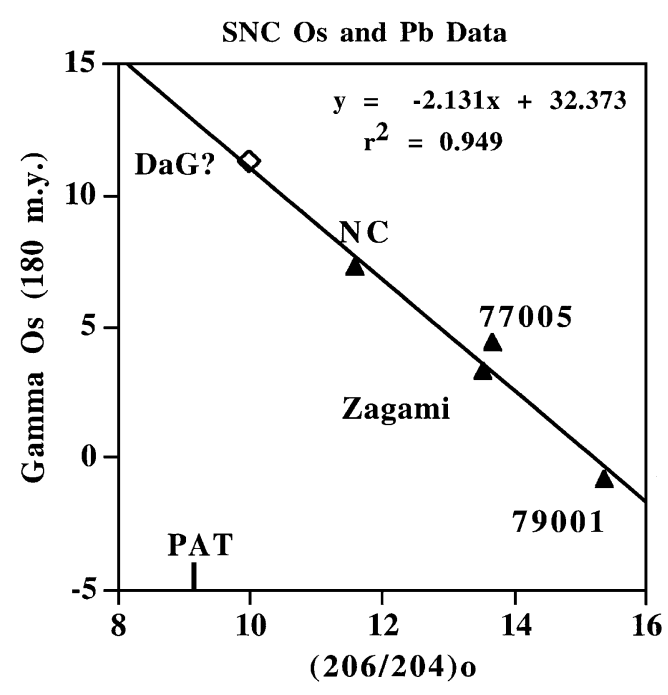

Fig. 17. Correlation between initial $\gamma(\mathrm{Os})$ and initial ${ }^{206} \mathrm{~Pb} /{ }^{204} \mathrm{~Pb}$ for four SNC meteorites [EET 79001; Zagami; ALH 77005; and Nakhla-Chassigny (NC)]. Here we use our revised $\gamma(\mathrm{Os})$ values, which we prefer to those of Brandon et al. (2000). If this inverse correlation were found to be robust, our prediction is that $\mathrm{DaG} 476$ will have a lead isotopic composition bracketed by NakhlaChassigny (NC) and primordial solar system $\mathrm{Pb}$ (PAT). Osmium data from Brandon et al. (2000) and this work; $\mathrm{Pb}$ data taken from the compilation of Jones (1989).

will have non-radiogenic $\mathrm{Pb}$. If our limiting calculation of $\gamma \mathrm{Os} \sim 11$ is correct, $\mathrm{DaG}$ should have $\mathrm{Pb}$ that approaches that of Cañon Diablo (PAT). However, it is possible, based on an oxide separate (Walker et al., 2002), DaG initial Os is more like that of Nakhla-Chassigny (NC). More work is necessary to determine the robustness of the correlation in Fig. 17 and to expand the database for $\mathrm{Pb}$.

\subsection{Hosts for the highly siderophile elements}

The lessons learned from Fig. 9 are: (i) that Os and Ir behave very similarly and that they can become strongly decoupled from the other siderophile elements; and (ii) that $\mathrm{Ru}$ can become modestly decoupled from Pd and Rh. Also, the HSE abundances correlate with basaltic fractionation indices such as $\mathrm{Mg} \#, \mathrm{Ni}$, and $\mathrm{Cr}$.

It is our view that such fractionations are unlikely to be caused by sulfides. It seems unlikely to us that sulfide fractionation would cause Os and Ir to decrease by a factor of $\sim 100 \mathrm{X}$, while leaving Re and Pt essentially unchanged.

It is also our view that these depletions in Os and Ir are unlikely to be caused by spinel. Spinel as a host for Os and Ir has been documented in terrestrial samples (Puchtel and Humayun, 2001) but not in SNC meteorites (A. Brandon, personal communication). Capobianco and Drake (1990) have shown that at high $f \mathrm{O}_{2}$, Ru partitions strongly into spinel and the analyses of Puchtel and Humayun (2001) indicate that $\mathrm{Ru}, \mathrm{Os}$, and Ir have similar chromite/komatiite partition coefficients $(D \sim 150)$. But Fig. 9 shows that, whereas $\mathrm{Ru}$ may decrease by a factor of $10 \mathrm{X}$ during igneous petrogenesis, Os and Ir decrease by a factor of 100X. This implies that Os and Ir partition coefficients into spinel must be $\sim 10 \mathrm{X}$ larger than those for $\mathrm{Ru}$. If $D^{\mathrm{Ru}}$ for spinel is $\sim 150$, this implies that $D^{\mathrm{Os}, \mathrm{Ir}}$ must be $>1000$. These values begin to approach those we would expect for sulfide/silicate partition coefficients $\left(\sim 10^{4}\right)$. For these reasons, we are uncertain that our terrestrial HSE experience will translate well to Mars. And, so far, analyses of SNC spinels have failed to document spinel as an important host of Os (A. Brandon, personal communication; Walker et al., 2002).

Another possibility is that Os and Ir partition more modestly into a major phase such as olivine (e.g., Barnes et al., 1985; Brügmann et al., 1987; but see Burton et al., 2002). Forty percent fractional crystallization of a phase with $D_{\mathrm{Os}} \sim 10$ would result in a factor of 100X decrease in Os. For comparison, for two percent fractional crystallization, the $D$ would have to be 230 to cause a $10 \mathrm{X}$ change. This is not terribly large $\left[D^{\mathrm{Ru}}\right.$ for spinel is already in that range (Capobianco and Drake, 1990).], but the observation still remains that $D^{\mathrm{Os}, \mathrm{Ir}}$ must be much larger than $D^{\mathrm{Ru}}$, whatever the host phase.

\section{Summary}

We have categorized the SNC meteorites in terms of their HSE element signatures into three different endmembers: primitive, evolved, and highly evolved. Some SNCs are transitional between these extremes. Variation in HSE signatures appears unrelated to crustal assimilation or petrologic type. We make predictions based on our HSE summary 
that some SNC finds have been contaminated with terrestrial Re. And we use correlations between HSE and minor elements such as $\mathrm{Ni}$ and $\mathrm{Cr}$ to evaluate difference in HSE analyses between different laboratories. We agree with others that the HSE signature of the martian mantle is close to chondritic, but we see no evidence that the siderophile signature of the martian mantle has evolved over time.

\section{Acknowledgements}

[RR]

\section{Appendix A}

Table A1

Analysis summary of highly siderophile elements in martian meteorites

\begin{tabular}{|c|c|c|c|c|c|c|c|c|}
\hline & Os & $\mathrm{Ir}$ & $\mathrm{Ru}$ & $\mathrm{Rh}$ & $\mathrm{Pd}$ & $\operatorname{Re}$ & $\mathrm{Pt}$ & $\mathrm{Au}$ \\
\hline \multicolumn{9}{|l|}{ Chassigny } \\
\hline Notre Dame & & 1.42 & 16.6 & 6.7 & 25.2 & & 6.2 & \\
\hline Chicago $^{1}$ & 1.36 & 1.85 & & & $<0.15$ & 0.054 & & 0.56 \\
\hline Paris $^{2}$ & 1.8 & & & & & 0.071 & & \\
\hline Mainz $^{3}$ & & 2.4 & & & & & & 1 \\
\hline Maryland $^{5}$ & $0.70-1.54$ & & & & & $0.13-0.46$ & & \\
\hline \multicolumn{9}{|l|}{ Dhofar 019} \\
\hline Notre Dame & & 0.13 & 0.35 & 0.3 & 1.7 & & 4 & \\
\hline Maryland $^{6}$ & 0.031 & & & & & $0.37^{\mathrm{a}}$ & & \\
\hline \multicolumn{9}{|c|}{ Dar al Gani 476} \\
\hline Notre Dame & & 1.6 & 5 & 3.9 & 15.2 & & 8.2 & \\
\hline Maryland $^{5}$ & $1.5-2.0$ & & & & & $0.50-0.63$ & & \\
\hline Mainz $^{7}$ & & $<2.5$ & & & & & & 2.1 \\
\hline \multicolumn{9}{|l|}{ Nakhla } \\
\hline Notre Dame & & 0.055 & 0.35 & 0.54 & 2.3 & & 4.4 & \\
\hline Chicago $^{1}$ & 0.2 & 0.15 & & & 42 & 0.041 & & 0.9 \\
\hline Paris $^{2}$ & $0.004-0.010$ & & & & & & & \\
\hline Tokyo $^{8}$ & 0.38 & 4.4 & & & & & 17.2 & 1 \\
\hline Maryland $^{5}$ & 0.014 & & & & & 0.052 & & \\
\hline \multicolumn{9}{|c|}{ Sayh al Uhaymir 005} \\
\hline Maryland $^{6}$ & 0.624 & & & & & 0.21 & & \\
\hline \multicolumn{9}{|l|}{ Shergotty } \\
\hline Notre Dame & & 0.23 & 1.77 & 1.16 & 16.3 & & 12 & \\
\hline Chicago $^{1}$ & $<0.0023$ & 0.028 & & & 1.7 & 0.044 & & 5 \\
\hline Mainz $^{4}$ & & 0.4 & & & & & & $0.9-6$ \\
\hline Purdue $^{4}$ & & & & & & & & $0.8-5.4$ \\
\hline \multicolumn{9}{|l|}{ Zagami } \\
\hline Notre Dame & & 0.15 & 0.41 & 0.43 & 3.1 & & 5 & \\
\hline Chicago $^{1}$ & 0.12 & 0.033 & & & 1.8 & 0.035 & & 1.8 \\
\hline \multicolumn{9}{|l|}{ Mainz $^{3}$} \\
\hline Purdue $^{3}$ & & & & & & & & 2.1 \\
\hline Maryland $^{5}$ & 0.0091 & & & & & 0.076 & & \\
\hline Tokyo $^{8}$ & 0.51 & 1.2 & & & & & 4.6 & 1.4 \\
\hline
\end{tabular}


Table A1 (continued)

\begin{tabular}{|c|c|c|c|c|c|c|c|c|}
\hline & Os & $\mathrm{Ir}$ & $\mathrm{Ru}$ & $\mathrm{Rh}$ & $\mathrm{Pd}$ & $\mathrm{Re}$ & $\mathrm{Pt}$ & $\mathrm{Au}$ \\
\hline \multicolumn{9}{|l|}{ ALH77005 } \\
\hline Notre Dame & & 3.6 & 4.4 & 1.3 & 4.7 & & 5.4 & \\
\hline Mainz $^{3}$ & & 3.5 & & & & & & 0.3 \\
\hline Maryland $^{5}$ & 3.4 & & & & & 0.256 & & \\
\hline Tokyo $^{8}$ & 9 & 9.11 & 3.6 & & & & 3.8 & 0.34 \\
\hline $\mathrm{UCLA}^{9}$ & 4.4 & 4.3 & & & & 0.102 & & 0.26 \\
\hline \multicolumn{9}{|l|}{ ALH84001 } \\
\hline Notre Dame & & 0.19 & 0.26 & 0.16 & 1.1 & & 0.96 & \\
\hline Tokyo $^{8}$ & 0.16 & 0.0061 & & & & & 2.3 & 0.07 \\
\hline $\mathrm{UCLA}^{10}$ & $0.01-0.012$ & $0.08-0.11$ & & & & $0.0013-0.0017$ & & 0.009 \\
\hline Maryland $^{6}$ & 0.0023 & & & & & $<0.001$ & & \\
\hline \multicolumn{9}{|l|}{ EET79001A } \\
\hline Notre Dame & & 0.59 & 1.6 & 0.88 & 6 & & 8.6 & \\
\hline Mainz $^{3}$ & & $<2$ & & & & & & 2.8 \\
\hline Maryland $^{5}$ & 0.48 & & & & & 0.099 & & \\
\hline Tokyo $^{8}$ & 1.5 & 1.64 & 2.2 & & & & 6.4 & 0.8 \\
\hline $\mathrm{UCLA}^{9}$ & $1.6-2.3$ & $1.4-2.0$ & & & & $0.085-0.23$ & & $0.8-0.92$ \\
\hline \multicolumn{9}{|l|}{ EET79001B } \\
\hline Notre Dame ${ }^{b}$ & & 0.36 & 0.74 & 1 & 4.5 & & 9.3 & \\
\hline Mainz $^{7}$ & & $<3$ & & & & & & $<2$ \\
\hline Maryland $^{5 b}$ & 0.16 & & & & & 0.066 & & \\
\hline Maryland $^{6}$ & $<0.01$ & & & & & 0.19 & & \\
\hline $\mathrm{UCLA}^{9}$ & $0.003-0.006$ & $0.0006-0.002$ & & & & $0.011-0.017$ & & $0.25-0.80$ \\
\hline \multicolumn{9}{|l|}{ LEW88516 } \\
\hline Maryland $^{5}$ & 0.9 & & & & & 0.022 & & \\
\hline UCLA $^{9 \mathrm{c}}$ & $1.8-3.3$ & $1.6-3.1$ & & & & $0.071-0.090$ & & $0.21-0.39$ \\
\hline \multicolumn{9}{|l|}{ QUE94201 } \\
\hline Mainz $^{7}$ & & $<3$ & & & & & & $<1.5$ \\
\hline $\mathrm{UCLA}^{9}$ & 0.005 & 0.012 & & & & 0.003 & & 0.041 \\
\hline \multicolumn{9}{|l|}{$Y 793605$} \\
\hline Tokyo $^{8}$ & 3.1 & 3.1 & 3 & & & & 2.8 & 0.18 \\
\hline $\mathrm{UCLA}^{9}$ & 2.7 & 2.2 & & & & 0.084 & & 0.22 \\
\hline Maryland $^{5}$ & 1.02 & & & & & 0.28 & & \\
\hline
\end{tabular}

${ }^{1}$ Treiman et al. (1986)—RNAA; ${ }^{2}$ Birck and Allègre (1994)—ID; ${ }^{3}$ Burghele et al. (1983)—INAA; ${ }^{4}$ Laul et al. (1986)—INAA; ${ }^{5}$ Brandon et al. (2000)—ID; ${ }^{6}$ Walker et al. (2002) —ID; ${ }^{7}$ Dreibus et al. (1996) —INAA; ${ }^{8}$ Kong et al. (1999)—RNAA; ${ }^{9}$ Warren et al. (1999) — RNAA; ${ }^{10}$ Warren and Kallemeyn (1996)-RNAA.

${ }^{\text {a }}$ Likely contains terrestrial Re contamination.

${ }^{\mathrm{b}}$ Probably a mixture of Lithologies A and B.

${ }^{c}$ One nonrepresentative analysis omitted. 
Table A2

Analyses of PGE standard rock WITS-1

\begin{tabular}{llllll}
\hline Element & \multicolumn{2}{l}{ Notre Dame analysis } & & \multicolumn{2}{l}{ Recommended values } \\
\cline { 2 - 3 } \cline { 6 - 6 } & $\begin{array}{l}\text { Abundance } \\
(\mathrm{ppb})\end{array}$ & $\begin{array}{l}\text { Error } \\
(2 \sigma)\end{array}$ & & $\begin{array}{l}\text { Abundance } \\
(\mathrm{ppb})\end{array}$ & $\begin{array}{l}\text { Error } \\
(2 \sigma)\end{array}$ \\
\hline $\mathrm{Ru}$ & 5.51 & 0.92 & & 5.1 & 1.2 \\
$\mathrm{Rh}$ & 1.11 & 0.21 & & 1.3 & 0.2 \\
$\mathrm{Pd}$ & 8.24 & 4.37 & & 7.9 & 0.9 \\
$\mathrm{Ir}$ & 1.69 & 0.22 & & 1.6 & 0.2 \\
$\mathrm{Pt}$ & 9.59 & 1.99 & & 11 & 2 \\
\hline
\end{tabular}

${ }^{\text {a }}$ Average of six replicates.

\section{References}

Agiorgitis, G., Wolf, R., 1984. Variations of the Os/Ir ratio in terrestrial rocks and minerals. Chem. Geol. 42, 277-286.

Barnes, S.J., Naldrett, A.J., Gorton, M.P., 1985. The origin of the fractionation of platinum group elements in terrestrial magmas. Chem. Geol. 53, 303-323.

Basaltic Volcanism Study Project, 1981. Basaltic Volcanism on the Terrestrial Planets. Pergamon, New York, pp. 282-310.

Beard, B.L., Taylor, L.A., Scherer, E.E., Johnson, C.M., Snyder, G.A., 1998. The source region and melting mineralogy of high-titanium and low-titanium lunar basalts deduced from Lu-Hf isotope data. Geochim. Cosmochim. Acta 62, $525-544$.

Birck, J.L., Allègre, C.L., 1994. Contrasting Re/Os magmatic fractionation in planetary basalts. Earth Planet. Sci. Lett. 124, $139-148$.

Borg, L.E., Nyquist, L.E., Taylor, L.A., Shih, C.-Y., 1997. Constraints on Martian differentiation processes from $\mathrm{Rb}-\mathrm{Sr}$ and $\mathrm{Sm}-\mathrm{Nd}$ isotopic analyses of the basaltic shergottite QUE94201. Geochim. Cosmochim. Acta 61, 4915-4931.

Borg, L.E., Nyquist, L.E., Wiesmann, H., Reese, Y., Papike, J.J., 2000. $\mathrm{Sr}-\mathrm{Nd}$ isotopic systematics of martian meteorite $\mathrm{DaG}$ 476 (Abstract). Lunar Planet. Sci., vol. XXXI. Lunar and Planetary Institute, Houston, p. 1036. CD-ROM.

Borg, L.E., Nyquist, L.E., Reese, Y., Wiesmann, H., Shih, C.-Y., Taylor, L.A., Ivanova, M., 2001. The age of Dhofar 019 and its relationship to the other martian meteorites (Abstract). Lunar Planet. Sci., vol. XXXII. Lunar and Planetary Institute, Houston, p. 1144. CD-ROM.

Borg, L.E., Nyquist, L.E., Wiesmann, H., Reese, Y., 2002. Constraints on the petrogenesis of Martian meteorites from the $\mathrm{Rb}-$ $\mathrm{Sr}$ and $\mathrm{Sm}-\mathrm{Nd}$ isotopic systematics of the lherzolitic shergottites ALH77005 and LEW88526. Geochim. Cosmochim. Acta 66, 2037-2053.

Brandon, A.D., Walker, R.J., Morgan, J.W., Goles, G.G., 2000. $\mathrm{Re}-\mathrm{Os}$ isotopic evidence for early differentiation of the martian mantle. Geochim. Cosmochim. Acta 64, 4083-4095.

Brügmann, G.E., Arndt, N.T., Hofmann, A.W., Tobschall, H.J., 1987. Noble metal abundances in komatiite suites from

Alexo, Ontario and Gorgona Island, Columbia. Geochim. Cosmochim. Acta 51, 2159-2169.

Burghele, A., Dreibus, G., Palme, H., Rammensee, W., Spettel, B., Weckwerth, G., Wänke, H., 1983. Chemistry of shergottites and the shergottite parent body (SPB): further evidence for the two component model for planet formation (Abstract). Lunar Planet. Sci., vol. XIV. Lunar and Planetary Institute, Houston, pp. $80-81$.

Burton, K.W., Schiano, P., Birck, J.-L., Allègre, C.J., Rehkämper, M., Halliday, A.N., Dawson, J.B., 2002. The distribution and behaviour of rhenium and osmium amongst mantle minerals and the age of the lithospheric mantle beneath Tanzania. Earth Planet. Sci. Lett. 183, 93-106.

Capobianco, C.J., Drake, M.J., 1990. Partitioning of ruthenium, rhodium, and palladium between spinel and silicate melt and implications for platinum group element fractionation trends. Geochim. Cosmochim. Acta 54, 869-874.

Capobianco, C.J., Drake, M.J., 1994. Partitioning and solubility of PGEs in oxides and silicates (abstract). Goldschmidt Conf., 144-145 (Edinburgh).

Chou, C.-L., Shaw, D.M., Crocket, J.H., 1983. Siderophile trace elements in the Earth's oceanic crust and upper mantle. Proc. Lunar Planet. Sci. Conf. 13th. J. Geophys. Res. 88, A507-A518 (Supplement).

Dreibus, G., Spettel, B., Wlotzka, F., Schultz, L., Weber, H.W., Jochum, K.P., Wänke, H., 1996. QUE94201: an unusual martian basalt (Abstract). Meteorit. Planet. Sci. 31, A39-A40.

Ely, J.C., Neal, C.R., 2002. Method of data reduction and uncertainty estimation for platinum-group element data using inductively coupled plasma-mass spectrometry. Geostand. Newsl. 26, 31-39.

Ely, J.C., Neal, C.R., 2003. Platinum-group elements in SNC meteorites: a coherent synthesis. Geochim. Cosmochim. Acta, to be submitted.

Ely, J.C., Neal, C.R., O’Neill Jr., J.A., Jain, J.C., 1999. Quantifying the platinum group elements (PGEs) and gold in geological samples using cation exchange pretreatment and ultrasonic nebulization inductively coupled plasma-mass spectrometry (USNICP-MS). Chem. Geol. 157, 219-234.

Harper, C.L., Nyquist, L.E., Bansal, B., Wiesmann, H., Shih, C.-Y., 1995. Rapid accretion and early differentiation of Mars indicated by ${ }^{142} \mathrm{Nd} /{ }^{144} \mathrm{Nd}$ in SNC meteorites. Science 267 , $213-217$.

Irving, A.J., 1978. A review of experimental studies of experimental crystal/liquid trace element partitioning. Geochim. Cosmochim. Acta 42, 743-770.

Jagoutz, E., 1996. Nd isotopic systematics of Chassigny (Abstract). Lunar Planet. Sci., vol. XXVII. Lunar and Planetary Institute, Houston, pp. $450-451$.

Jakosky, B.M., Jones, J.H., 1997. The history of martian volatiles. Rev. Geophys. 35, 1-16.

Jones, J.H., 1986. A discussion of isotopic systematics and mineral zoning in the shergottites: evidence for a 180 m.y. igneous crystallization age. Geochim. Cosmochim. Acta 50, 969-977.

Jones, J.H., 1989. Isotopic relationships among the shergottites, the nakhlites and Chassigny. Proc. Lunar Planet. Sci. Conf. 19th. Lunar and Planetary Institute, Houston, pp. 465-474. 
Jones, J.H., Drake, M.J., 1986. Geochemical constraints on core formation in the Earth. Nature 322, 221-228.

Kong, P., Ebihara, M., Palme, H., 1999. Siderophile elements in Martian meteorites and implications for core formation in Mars. Geochim. Cosmochim. Acta 63, 1865-1875.

Laul, J.C., Smith, M.R., Wänke, H., Jagoutz, E., Dreibus, G., Palme, H., Spettel, B., Burgehele, A., Lipschutz, M.E., Verkouteren, R.M., 1986. Chemical systematics of the Shergotty meteorite and the composition of its parent body (Mars). Geochim. Cosmochim. Acta 50, 909-926.

Longhi, J., 1991. Complex magmatic processes on Mars: inferences from SNC meteorites. Proc. Lunar Planet. Sci. Conf. 21st. Lunar and Planetary Institute, Houston and Cambridge U. Press, pp. $465-475$.

McCandless, T.E., Ruiz, J., Adair, B.I., Freydier, C., 1999. Re-Os isotope and $\mathrm{Pd} / \mathrm{Ru}$ variations in chromitites from the Critical Zone, Bushveld Complex, South Africa. Geochim. Cosmochim. Acta 63, 911-923.

McSween Jr., H.Y., Jarosewich, E., 1983. Petrogenesis of the EETA79001 meteorite: multiple magma pulses on the shergottite parent body. Geochim. Cosmochim. Acta 47, 1501-1513.

McSween Jr., H.Y., Eisenhour, D.D., Taylor, L.A., Wadhwa, M., Crozaz, G., 1996. QUE 94201 shergottite: crystallization of a martian basaltic magma. Geochim. Cosmochim. Acta 60 , 4563-4569.

Meisel, T., Walker, R.J., Irving, A.J., Lorand, J.-P., 2001. Osmium isotopic compositions of mantle xenoliths: a global perspective. Geochim. Cosmochim. Acta 65, 1311-1323.

Meyer, C., 1998. Mars Meteorite Compendium-1998. NASA Johnson Space Center. JSC \#27672. 237 pp.

Mittlefehldt, D.W., Lindstrom, M.M., 1996. Martian meteorites QUE94201, an unusual basalt, and Governador Valadares, a typical clinopyroxenite: geochemistry (abstract). Lunar Planet. Sci., vol. XXVII. Lunar and Planetary Institute, Houston, pp. $887-888$.

Morgan, J.W., 1986. Ultramafic xenoliths: clues to Earth's late accretionary history. J. Geophys. Res. 91, 12375-12387.

Nakamura, N., Komi, H., Kagami, H., 1982. Rb-Sr isotopic and REE abundances in the Chassigny meteorite (Absract). Meteoritics $17,257-258$.

Neal, C.R., Taylor, L.A., Ely, J.C., Jain, J.C., 2001. Detailed geochemistry of new shergottite, Dhofar 019 (Abstract). Lunar Planet. Sci., vol. XXXII. Lunar and Planetary Institute, Houston, p. 1671.

Newsom, H.E., 1995. Composition of the solar system, planets, meteorites, and major terrestrial reservoirs. In: Ahrens, T.J. (Ed.), Global Earth Physics, A Handbook of Physical Constants. AGU Reference Shelf, vol. 1, pp. 159-189.

Nyquist, L.E., Reese, Y.D., Wiesmann, H., Shih, C.-Y., Schwandt, C., 2000. Rubidium-Strontium age of the Los Angeles shergottite (Abstract). Meteorit. Planet. Sci. 35, A121.

Ott, U., 1988. Noble gases in SNC meteorites: Shergotty, Nakhla, Chassigny. Geochim. Cosmochim. Acta 52, 1937-1948.

Puchtel, I.S., Humayun, M., 2001. Platinum group element fractionation in a komatiitic basalt lava lake. Geochim. Cosmochim. Acta 65, 2979-2993.
Rehkämper, M., Halliday, A.N., Fitton, J.G., Lee, D.-C., Wieneke, M., Arndt, N.T., 1999. Ir, Ru, Pt, and Pd in basalts and komatiites: new constraints for the geochemical behavior of the platinum-group elements in the mantle. Geochim. Cosmochim. Acta 63, 3915-3934.

Righter, K., Walker, R.J., Warren, P.H., 2000. Significance of highly Siderophile elements and osmium isotopes in the lunar and terrestrial mantles. Origin of the Earth and Moon. Univ. of Arizona Press, Tucson, AZ, pp. 291-322.

Schiano, P., Birck, J.-L., Allègre, C.J., 1997. ${ }^{187} \mathrm{Os} /{ }^{188} \mathrm{O}$ ratios of mid-ocean ridge basalts: tracing crust recycling in the mantle. Earth Planet. Sci. Lett. 150, 363-379.

Shih, C.-Y., Nyquist, L.E., Bogard, D.D., McKay, G.A., Wooden, J.L., Bansal, B.M., Wiesmann, H., 1982. Chronology and petrogenesis of young achondrites, Shergoty, Zagami, and ALHA7705. Geochim. Cosmochim. Acta 46, 2323-2344.

Shih, C.-Y., Nyquist, L.E., Wiesmann, H., 1996. Sm-Nd systematics of nakhlite Govenador Valadares (Abstract). Lunar Planet. Sci., vol. XXVII. Lunar and Planetary Institute, Houston, pp. 1197-1198.

Shih, C.-Y., Nyquist, L.E., Reese, Y., Wiesmann, H., 1998. The chronology of the nakhlite Lafayette: $\mathrm{Rb}-\mathrm{Sr}$ and $\mathrm{Sm}-\mathrm{Nd}$ isotopic ages (Abstract). Lunar Planet. Sci., vol. XXIX. Lunar and Planetary Institute, Houston, p. 1145. CD-ROM.

Shih, C.-Y., Nyquist, L.E., Wiesmann, H., 1999. Samarium-neodymium and rubidium-strontium systematics of nakhlite Govenador Valadares. Meteorit. Planet. Sci. 34, 647-655.

Shirey, S.B., Walker, R.J., 1998. The Re-Os system in cosmochemistry and high-temperature geochemistry. Annu. Rev. Earth Planet. Sci. 26, 423-500.

Taylor, L.A., Nazarov, M.A., Ivanova, M.A., Patchen, A., Clayton, R.N., Mayeda, T.K., 2000. Petrology of the Dhofar 019 shergottite (Abstract). Meteorit. Planet. Sci. 35, A155.

Treiman, A.H., Drake, M.J., Janssens, M.-J., Wolf, R., Ebihara, M., 1986. Core formation in the Earth and shergottite parent body (SPB): chemical evidence from basalts. Geochim. Cosmochim. Acta 50, 1071-1091.

Wadhwa, M., 2001. Redox state of Mars' upper mantle and crust from $\mathrm{Eu}$ anomalies in shergottite pyroxenes. Science 291, $1527-1530$.

Walker, R.J., Brandon, A.D., Nazarov, M.A., Mittlefehldt, D., Jagoutz, E., Taylor, L.A., 2002. ${ }^{187} \mathrm{Re}-{ }^{187} \mathrm{Os}$ isotopic studies of SNC meteorites: an update (Abstract). Lunar Planet. Sci., vol. XXXIII. Lunar and Planetary Institute, Houston, p. 1042. CDROM.

Wänke, H., 1981. Constitution of the Terrestrial Planets. Philos. Trans. R. Soc. Lond. A303, 287-302.

Warren, P.H., Kalleymeyn, G.W., 1996. Siderophile trace elements in ALH84001, other SNC meteorites and eucrites: evidence of heterogeneity, possibly time-linked, in the mantle of Mars. Meteorit. Planet. Sci. 31, 97-105.

Warren, P.H., Kallemeyn, G.W., Kyte, F.T., 1999. Origin of planetary cores: evidence from highly siderophile elements in martian meteorites. Geochim. Cosmochim. Acta 63, 2105-2122. 